\title{
DERECHOS HUMANOS Y JUSTICIA PENAL EN MÉXICO: UN ENFOQUE REFLEXIVO DESDE EL DERECHO POSMODERNO
}

\author{
HUMAN RIGHTS AND CRIMINAL JUSTICE IN MEXICO: A \\ REFLECTIVE APPROACH FROM THE POSMODERN RIGHT
}

\author{
GEOFREDO ANGULO LÓPEZ*
}

Recibido: 28/04/2017

Aceptado: 07/11/2017

\begin{abstract}
Sumario: I. EL DERECHO EN CLAVE POSMODERNISTA: UN ENFOQUE DESDE LA TEORÍA DE FRANÇOIS OST. II. EL JUEZ HERMES EN EL DERECHO POSMODERNO: UN ENFOQUE CRÍTICO A LA JUSTICIA PENAL DESDE LA EFICACIA Y LEGITIMACIÓN SOCIAL. III. DERECHOS HUMANOS Y POSMODERNIDAD: NUEVOS RASGOS Y CONCEPCIONES EN EL PARADIGMA CONSTITUCIONAL.

Summary: I. THE RIGHT IN POSMODERNIST KEY: AN APPROACH FROM THE THEORY OF FRANÇOIS OST. II. JUDGE HERMES IN THE POSTMODERN LAW: A CRITICAL APPROACH TO CRIMINAL JUSTICE SINCE EFFECTIVENESS AND SOCIAL LEGITIMATION. III. HUMAN RIGHTS AND POSMODERNITY: NEW FEATURES AND CONCEPTIONS IN THE CONSTITUTIONAL PARADIGM.
\end{abstract}

Resumen: La transición paradigmática de la teoría jurídica ha puesto a los derechos humanos como el eje central de la ingeniería constitucional, originando un cambio en los métodos para estudiar los sistemas jurídicos contemporáneos. En este sentido, en México, los derechos humanos empiezan a adquirir nuevos rasgos definitorios que vienen a formar parte de un derecho posmoderno complejo, múltiple, dúctil e intersticial, que origina una nueva forma de entender la validez constitucional de los derechos y principios de una realidad jurídica y social, cada vez más global, cibernética, y digital. En este contexto, la hermenéutica que exige este nuevo paradigma, supone una revisión a la concepción tradicional de los derechos humanos y de la dignidad, así como de los mecanismo en los sistemas de justicia penal con los que opera para cumplir con su función de dar seguridad a la sociedad; pues los desafíos, alcances e implicaciones que tiene este paradigma sobre la juridicidad aún no se descifran.

Palabras clave: Derecho posmoderno, derechos humanos, multiplicidad, constitucionalidad, ductilidad, vaguedad, paradigma, paradoja.

\footnotetext{
* Doctor en derechos fundamentales por la Universidad de Jaén, Andalucía, España. Investigador de la Comisión de Derechos Humanos del Estado de Yucatán (México) y catedrático de la Facultad de Derecho de la Universidad Autónoma de Yucatán (México) Miembro del Sistema Nacional de Investigadores. geofreyangulo@gmail.com
} 
Abstract: The paradigmatic transition of legal theory has put human rights as the central axis of constitutional structure, leading to different methods in order to study contemporary legal systems. In this sense, in Mexico, human rights begin to acquire new defining features that are part of a complex, multiple, ductile and interstitial postmodern right, which generate to a new way of understanding the constitutional validity of rights, and principles, of A juridical and social reality, increasingly global, cybernetic, and digital. In this context, the hermeneutics required by this new paradigm involves a revision of the traditional conception of human rights and dignity, as well as of the mechanisms in the criminal justice systems with which it operates to fulfill its function of giving Security to society; Because the challenges, scope and implications of this paradigm on legality have not yet been deciphered

Keywords: Postmodern law, human rights, multiplicity, normative network, ductility, vagueness, paradigm, paradox.

\section{EL DERECHO EN CLAVE POSMODERNISTA: UN ENFOQUE DESDE LA TEORÍA DE FRANÇOIS OST}

Frente a la crisis del Estado posmoderno y del Estado de Bienestar, se nos presenta una realidad jurídica y social cada vez más global y cibernética, cuyos retos, alcances e implicaciones que tienen sobre la juridicidad aún no se descifran. Esto nos lleva a suponer, que la complejidad que se nos presenta es mucho mayor que el moderno artificio teórico jurídico. Desde esta perspectiva, la configuración de un nuevo modelo parece fundamental. Para François Ost, el derecho, como signo lingüístico, exige ser interpretado por sus destinatarios, y, como manifestación de la voluntad, ser interiorizado y aceptado. De manera que, desde el momento en que lo sujetos de derecho reconstruyen mentalmente el mensaje que se les dirige y mediatizan su puesta en práctica con una operación de voluntad, el derecho se configura como algo necesariamente inacabado, en constante transformación y retomado en la mediación del cambio. Esta aproximación ontológica, para François Ost, podría, a su vez ser desarrollada y perseguida bajo la descripción de las formas inéditas que toman los sistemas jurídicos posmodernos. ${ }^{1}$

Para François Ost, son varias las realidades que hacen surgir un derecho posmoderno. Como primer signo de esta realidad, aparece la multiplicidad de actores jurídicos, entre los cuales destaca el juez con su norma de decisión; ${ }^{2}$ el legislador, que evidentemente se

\footnotetext{
${ }^{1}$ Vid; OST, F., “Júpiter, Hércules, Hermes: tres modelos de juez”, Academia, Revista sobre la Enseñanza del Derecho, Universidad de Buenos Aires, año 4, $\mathrm{n}^{\circ}$ 8, 2007, p. 117. Publicado originalmente en Doxa, $\mathrm{n}^{\circ} 14$, 1993.

${ }^{2}$ La norma de decisión resultará de llevar plenamente el proceso de la interpretación hasta su punto máximo; es decir, una norma jurídica se produce para aplicarse de manera fundada, adecuada, correcta, y justificada a un caso concreto. Esta operación se realiza mediante la formulación de una decisión judicial, una sentencia, que expresa la norma de decisión. En base a esto es que podemos establecer la diferencia entre (normas
} 
despliega en normas; y, que a pesar de que vemos con acierto como muchas de ellas permanecen vigentes aun cuando han perdido toda su vigencia sociológica, ${ }^{3}$ la codificación como técnica tradicional que se creía en desuso, sigue estando de moda. Es evidente que estamos en un momento de alta producción normativa, en la que nuevos actores se suman a este proceso de manufactura legal; nos referimos concretamente a los particulares, las personas morales, las empresas y las asociaciones inmersas en el tránsito de las normas jurídicas. Es indiscutible, que los derechos humanos han mutado parcialmente su naturaleza primigenia para convertirse en estatus jurídicos que no solo garantizan la libertad frente al Estado, sino también frente a otros particulares. ${ }^{4}$

Esta realidad se presenta en México, a partir de la reforma constitucional en materia de derechos humanos de junio de 2011, en la que se puede constatar ya una evolución dogmática y jurisprudencial de los efectos horizontales de los derechos humanos ${ }^{5}$ o de la eficacia entre particulares de estos derechos, ${ }^{6}$ desarrollándose una concepción más amplia de los derechos humanos, en el que aparece el papel esencial de los actores responsables y de los usuarios en la incorporación de estos potenciales jurídicos. Es importante destacar que, no puede ya negarse la multiplicidad de derechos humanos que despliegan sus efectos en esas relaciones privadas; piénsese en el derecho al honor, a la intimidad y a la propia imagen, la libertad de expresión, en los derechos del ámbito laboral, de asociación, etc. Este crecimiento en el objeto de los derechos humanos se explica, en buena medida, por la fuerza expansiva que han adquirido como categorías jurídicas que sustentan la esencia misma del sistema democrático y del ordenamiento jurídico en su conjunto.

Esto conduce a formular un segundo indicio de complejidad: la multiplicidad de los niveles de poder. A la división que separa, en el marco de las funciones del poder público,

jurídicas y la norma de decisión), la cual se define a partir de aquellas. Así, el juez es el que va más allá de la interpretación como una mera producción de normas jurídicas, para extraer de ella normas de decisión. Vid; GRAU, E., Interpretación y aplicación del derecho, Madrid, ed. Dykinson, 2007, pp.18-19.

${ }^{3}$ vid; BIDART CAMPOS, G., Teoría general de los derechos humanos, Buenos Aires, ed. Astrea, 1991, 314315.

${ }^{4}$ Vid; PÉREZ TREMPS, P., Escritos sobre justicia constitucional, México D.F., Ed. Porrúa (Instituto Mexicano de Derecho Procesal Constitucional), 1. ${ }^{\mathrm{a}}$ edición, 2005, p.111.

${ }^{5}$ Como introducción a la teoría de la eficacia horizontal de los derechos, vid; JULIO ESTRADA, A., La eficacia de los derechos fundamentales entre particulares, Bogotá, Universidad Externado de Colombia, 2001.

${ }^{6}$ En efecto, en la actualidad esta es una de las cuestiones centrales en la teoría iusfundamental europea de lo que se denomina la eficacia de los derechos fundamentales frente a particulares, (Drittwirkung der Grundrechte), denominación que busca inicialmente, ante todo, destacar el nuevo destinatario de los derechos fundamentales, los terceros, frente a la tradicional vinculación estatal. Sobre la eficacia de los derechos fundamentales en las relaciones entre particulares, un estudio muy completo, puede consultarse en; VENEGAS GRAU, M., Derechos fundamentales y derecho privado. Los derechos fundamentales en las relaciones entre particulares y el principio de autonomía privada, Madrid-Barcelona, Ed. Marcial Pons, 2004, (prólogo de Rafael de Asís Roig); Más específicamente, vid; GUTIÉRREZ GUTIÉRREZ, I., "Criterios de eficacia de los derechos fundamentales en las relaciones entre particulares”, Teoría y Realidad Constitucional, N 3, 1999. 
la sociedad civil organizada, organismos regionales e internacionales, los partidos políticos, los medios de comunicación de radio y televisión, los órdenes jurídicos supranacionales; se ha incorporado a esta estratificación densa de poderes, el poder de la informática e internet o, más propiamente citado, “las tecnologías de la información”. El internet tiene su origen en 1983 cuando distintas redes informáticas con la misma tecnología se unen creando la llamada red de redes; que con su comercialización motivó el inicio de una nueva era cibernética y de un nuevo paradigma científico; ${ }^{7}$ o como señala Roszak, del inicio de una era que propuso nuevos retos éticos, desde una tecnología que toma la "capacidad de concentrar el poder político, de crear nuevas formas de ofuscación y dominación de la sociedad". ${ }^{8}$ Ciertamente Sartori ya profetizaba en su obra Homo videns, que en un futuro la población de los países opulentos tendría en sus casas, además de la televisión, un mini ordenador; ${ }^{9}$ pues bien, la realidad actual, es que el mini ordenador se ha convertido en el Smartphone y está al alcance de aproximadamente dos mil millones de usuarios en el mundo. $^{10}$

En efecto, en esta civilización cibernética, del Facebook, del comercio en la web, los países se convierten en unidades extraterritoriales de una cultura y un lenguaje compartido. Solíamos saber que una nación estaba conformada por muchos elementos, como por ejemplo, el territorio, la lengua, etc., actualmente un país se presenta como un conjunto de personas móviles con una lógica vital profundamente implantada en el consumismo y en un sentimiento colectivo de aprobación de sus comportamientos por parte de los integrantes de esta aldea global. ${ }^{11}$ Justamente una de las características que define la teoría de Marshall McLuhan, ${ }^{12}$ se percibe, cuando afirma que: "también el medio es el mensaje, donde la tecnología modifica al hombre, ya que el medio de comunicación influye, determina y nos moldea". ${ }^{13}$ Por lo tanto, es, en este espacio virtual donde se suscita un reto para la jurisdicción respecto a las transacciones realizadas en un mundo en donde el territorio es ficción y por momentos sin materialidad. Por ejemplo, cada vez es más difícil determinar el ámbito espacial de validez en la web, definir las reglas que se deben aplicar a los

\footnotetext{
${ }^{7}$ Vid; DE ASÍS ROIG, R., Una mirada a la robótica desde los derechos humanos, Madrid, UC3-Dykinson, 2015, p. 25.

${ }^{8}$ ROSZAK, T., El culto a la información. Un tratado sobre, alta tecnología, inteligencia artificial y al verdadero arte de pensar, Barcelona, Gedisa, 2005, p. 12. (Trad., de J. Beltrán).

${ }^{9}$ SARTORI, G., Homo videns. La sociedad teledirigida, Argentina, Taurus, 1998, p. 12.

${ }^{10} \mathrm{http}: / / \mathrm{www} . c$ lasesdeperiodismo.com/2014/12/23/en-2016-habra-dos-mil-millones-de-usuarios-desmartphones-en-el-mundo/ [Accedido el día 24 de abril de 2017].

${ }^{11}$ Término acuñado por el sociólogo canadiense Marshall McLuhan, quien en 1968 lo utilizó en el título de su libro Guerra y paz en la Aldea Global.

${ }^{12}$ Herbert Marshall McLuhan (1911-1980), escritor canadiense que abordó en su obra el tema de la comunicación. Su teoría, “el medio es el mensaje”, se convirtió en el lema de la contracultura de la década de 1960. Nació en Edmonton (Alta), y estudió en las universidades de Manitoba y Cambridge. Impartió cátedra en diversas universidades de Canadá y Estados Unidos.

${ }^{13}$ MARSHALL MCLUHAN, H., Comprender los medios de comunicación. Las extensiones del ser humano, Barcelona, Paidós, 1996, pp. 29-43. Título original: "Understanding Media. The Extensions of Man”. Publicado en inglés por The MIT Press, Cambridge, Massachusetts, (Trad. Patrick Ducher).
} 
consumidores y proveedores que se encuentran en diferentes países y que llevan a cabo contratos de compraventa en la web. ${ }^{14}$

En este sentido, Mancini analizando la teoría pura del derecho de Kelsen, -teoría que sirvió de base en la construcción de los sistemas jurídicos actuales-, llega a la conclusión que la teoría de Kelsen depende plenamente de la existencia de un código escrito, es decir, de una memoria de textos jurídicos. ${ }^{15}$ La teoría de Kelsen fue construida sobre la idea de un Estado asentado en un territorio. De tal manera que fijar al ámbito de validez de una norma jurídica que circula en los circuitos de la red manifestando su voluntad y creando nuevos vínculos jurídicos, resulta complejo; pues en internet no hay territorios, no le hacen falta para existir y, por consiguiente, rompe el principio de jurisdicción en el que se basa la premisa de Kelsen; Mancini lo describe claramente al señalar que: "Un mundo jurídico clásico atado desde sus orígenes a la tierra, solo puede quedar perplejo y desorientado frente a un mundo virtual sin tierra y sin fronteras". ${ }^{16}$

Llegado a este punto, es claro, que vivimos en un mundo múltiple pero cada vez más reducido, dentro del cual, la informática e internet han traído como consecuencia un gran impacto en el orden social; por un lado, conocemos en tiempo real lo que acontece en cualquier parte del mundo, pero a la par vamos perdiendo la capacidad de indignación, ${ }^{17}$ de reaccionar ante las necesidades y sufrimiento de los demás; es una realidad innegable, como las personas reaccionan como si algo le ocurriera no a personas, sino a objetos físicos, a cosas, y no a humanos. Zygmunt Bauman sostiene que en esta modernidad líquida, el mal ha adquirido nuevas formas; una de ellas se refiere a la ausencia de empatía, “al negarse a comprender a los demás, en la insensibilidad y en los ojos apartados de una silenciosa mirada ética”. ${ }^{18}$ Para Zygmunt Bauman, es indudable, que en esta era cibernética, las tecnologías de la información han superado a la política, simultáneamente vemos como se ha transformado en un suplemento de la tecnología que amenaza con culminar en la creación de una sociedad informatizada. Así, "la tecnología ha dejado atrás a la política. O te involucras activamente en el mundo de las tecnologías informáticas o dejas de existir. 'Puedes', por lo tanto 'deberías'. Puedes estar conectado; por lo tanto, deberías estar conectado. Si no lo estás dejas de participar en la realidad”. ${ }^{19}$ Aquí, la cuestión principal,

\footnotetext{
${ }^{14}$ Vid; RUZ SALDÍVAR, C., / MALDONADO MÉNDEZ, E. V., Reflexiones sobre la constitución como la norma fundamental a la luz del nuevo orden jurídico internacional, ponencia inédita presentada en el XIII Congreso Iberoamericano de Derecho Constitucional, Ciudad de México, 2017.

${ }^{15}$ Vid; MANCINI, A., Justicia e internet, una filosofía del derecho para el mundo virtual, Paris, Francia, Editorial Buenos Books America, 2004, p. 3.

${ }^{16}$ MANCINI, A., Justicia e internet, una filosofía del derecho para el mundo virtual, Op. Cit., pp. 1-5.

${ }^{17}$ Stéphane Hessel en su obra ¡Indignaos!, invita a los jóvenes a desesperarse y a transformar la indiferencia por una indignación activa. “iINDIGNÁOS!, les dice Hessel a los jóvenes, porque de la indignación nace la voluntad de compromiso con la historia”. Vid: prólogo de José Luis Sampedro, en, HESSEL, S., ¡Indignaos!, Barcelona, ed. Destino, 2011, p. 4. (Trad. Telmo Moreno Lanaspa).

${ }^{18}$ BAUMAN, Z., / DONSKIS, L., Ceguera moral. La pérdida de sensibilidad en la modernidad líquida, Barcelona, Paidós, 2015, p. 15-19.

${ }^{19}$ BAUMAN, Z., / DONSKIS, L., íd., pp. 69-73.
} 
es, si estás conectado o no respecto a la realidad de regiones donde ni siquiera la modernidad ha llegado, a los problemas trascendentes, exigencias y necesidades de tu país $\mathrm{y}$ a los debates generados en torno a ellos, en lugar de decidir finalmente si permaneces en un mismo lugar y votas a los mismos actores políticos para siempre. Este es el plebiscito diario de la moderna sociedad líquida. ${ }^{20}$

\section{EL JUEZ HERMES EN EL DERECHO POSMODERNO: UN ENFOQUE CRÍTICO A LA JUSTICIA PENAL DESDE LA EFICACIA Y LEGITIMACIÓN SOCIAL}

Para François Ost, en este contexto del derecho posmoderno, surge el juez Hermes como el modelo de los jueces del siglo XXI. El derecho posmoderno para este jurista belga, es un derecho en red, es decir, el derecho se aplica y se crea a manera de red, en la cual el juez Hermes aparece como un componedor intermedio, se encuentra en permanente dialéctica con todas las fuentes del derecho sin dar omnipotencia a alguna de ellas. ${ }^{21}$ François Ost propone representar este paradigma bajo los rasgos de Hermes, el "juez red”, reflejo de las exigencias, intereses y complejidades de una sociedad en transformación. Si la pirámide representa el señorío del juez júpiter, (superioridad de la ley), ${ }^{22}$, y el embudo al pragmatismo del juez Hércules,(superioridad de la jurisprudencia), ${ }^{23}$ la trayectoria que dibuja Hermes en el campo jurídico adopta la forma de red en la cual circulan los discursos, lo significados e informaciones disponibles instantáneamente, y, al mismo tiempo difícilmente matizables, por no dejarse ya contener en un código o en un dossier; sino que

\footnotetext{
${ }^{20}$ Tan simple como eso afirmaba Donskis en una interesante discusión en el Frankfurter Rundschau el 26 de septiembre de 1992. Vid; BAUMAN, Z., / DONSKIS, L., íd., p. 74,

${ }^{21}$ Vid; OST, F., “Júpiter, Hércules, Hermes: tres modelos de juez”, Op. Cit., pp. 101-105

${ }^{22}$ El juez júpiter es quien responde a lo estricto de la pirámide Kelseniana, crea y aplica el derecho con base en un stricti iuris o normativismo rígido; al código lo sustituye el dossier, la singularidad y lo concreto del caso se superponen a la generalidad y abstracción de la ley. Es el modelo jurídico clásico que se sigue enseñando en algunas universidades y que aún ciertos jueces conservan en sus razonamientos la forma lineal y unidireccional en la aplicación práctica e interpretación del derecho. El paradigma de la pirámide y del código predominante de una justicia inspirada por el mandato jupiterino, le sustituye la balanza, ajustando lo proporcional a nuestros cálculos y ponderando los intereses en conflicto o en colisión. Vid; OST, F., "Júpiter, Hércules, Hermes: tres modelos de juez”, Op. Cit., pp. 105-108.

${ }^{23}$ Es Ronald Dworkin quien reflexionando sobre la idea de un juez moderno, piensa en el personaje de Hércules; un juez semidiós que se somete a un proceso incansable de juzgar. Para este juez no hay más derecho que el jurisprudencial; es la decisión y no la ley la que crea autoridad. Es un juez racional que toma los derechos humanos en serio, que "domina el imperio del derecho, que se consagra en toda ocasión, y particularmente en los casos difíciles, a encontrar la respuesta correcta que se impone. Vid; OST, F., "Júpiter, Hércules, Hermes: tres modelos de juez”, Op. Cit., pp. 109-110 y 169-174. También vid; ATIENZA, M., “Sobre la única respuesta correcta," Revista Jurídicas, Vol. 6, n 2, Colombia, Julio-Diciembre, 2009, p. 14. Sobre la figura del Juez Hércules vid; DWORKIN, R., Los derechos en serio, Barcelona, Ariel derecho, $1^{\circ}$ Edición 1984. (Traducción Marta Guastavino). Del mismo autor vid; El Imperio de la justicia, Barcelona, Gedisa, $2^{a}$ Edición 1992 (Traducción Claudia Ferrari). Sobre un punto de vista crítico a la teoría de la única respuesta correcta vid; AARNIO A., ATIENZA, M., LAPORTA F., Bases teóricas de la interpretación jurídica, Madrid-México, Fontamara, $1^{\text {a }}$ ed. 2013, pp. 9-137.
} 
se expresa bajo la forma de un banco de datos que se interrelacionan con una multitud de puntos, poderes, actores, roles, que se diversifican y se invierten. Para Ost, Hermes representa todo actor jurídico, todo aquel que se expresa en el discurso jurídico, pero atendiendo la actitud hermenéutica que representa el modelo de Hermes. Es un juez para el que la voluntad del autor del texto legal solo representa un elemento entro otros que concurren a determinar el sentido óptimo de las normas a interpretar; un jurista que se esfuerza por integrar, en la construcción del sentido jurídico, nuevos posicionamientos dogmáticos y creaciones normativas de otros sistemas jurídicos. ${ }^{24}$

Hermes preocupado por la justicia del futuro, reflexiona sobre los nuevos retos éticos y jurídicos que plantean el desarrollo tecnológico en relación a la informática e internet, biomedicina, neurociencias, nanociencia y nanotecnología, la robótica) ${ }^{25}$ y la inteligencia artificial aplicada al derecho ${ }^{26}$ como un sistema experto que abriría el paso al juezrobot. ${ }^{27}$ Para Hermes, esta relación de ejecución tecnológica y de autoridad volitiva nos deja ver un desequilibrio profundamente desestabilizador; de modo que el desafío de la sociedad

\footnotetext{
${ }^{24}$ Vid; OST, F., “Júpiter, Hércules, Hermes: tres modelos de juez”, Op. Cit., p. 104.

${ }^{25}$ Sobre las problemáticas y exigencias que plantea el derecho actual en el contexto de las tecnologías emergentes vid; DE ASÍS, R., Una mirada a la robótica desde los derechos humanos, Op. Cit., pp. 23.34.

${ }^{26}$ La utilización de la tecnología en la aplicación del derecho ha demostrado que el conocimiento jurídico puede ser modelado para crear programas informáticos que puedan simular procesos cognitivos. Así, los sistemas expertos jurídicos, conforman la principal aplicación de la inteligencia artificial en la ciencia jurídica. Como sistema basado en el conocimiento, funciona como auxiliar en la toma de decisiones de los jueces. Sobre la relación que mantienen los programas de inteligencia artificial con el derecho, vid; BOURCIER, D., Inteligencia artificial y derecho, Barcelona, Universitat Oberta de Catalunya, 2003.

${ }^{27}$ Este tipo de sistema fue creado en México en el Instituto de Investigaciones Jurídicas por el jurista Enrique Cáceres Nieto, quien sostiene que la principal ventaja que presenta este tipo de sistema frente al modelo positivista explícito, es que concibe a la norma jurídica no como los enunciados explícitos contenidos en los cuerpos normativos a los que comúnmente se les identifica con el término derecho objetivo, sino al esquema mental resultante del procesamiento de tales enunciados mediante reglas de razonamiento jurídico, los cuales se integran con otros conocimientos con que se cuenta el operador jurídico, tales como los provenientes del discurso de la teoría general del derecho, de las teorías acerca de las actividades jurídicas (argumentación e interpretación), o de la dogmática jurídica (términos con sus campos semánticos específicos, estructuraciones semánticas, técnicas de interpretación, etc. Vid; CÁCERES NIETO, E., "Las teorías jurídicas como realidades hermenéuticas”, Boletín Mexicano de Derecho Comparado, nueva serie, año XXXV, núm. 103, enero-abril de 2002, pp. 27-62. También vid; MARTÍNEZ BAHENA G. C., "La inteligencia artificial y su aplicación al campo del derecho", Alegatos, $\mathrm{n}^{\circ}$ 82, 2012, pp. 836-837. Este modelo ha recibido diversas críticas, como por ejemplo, en relación con el mantenimiento y actualización del banco de datos. El derecho actual es veloz; constantemente surgen reformas a los contenidos normativos de los derechos originando nuevos criterios. Además existe la posibilidad de la inexistencia en el ordenamiento jurídico de un enunciado normativo en relación al supuesto de hecho. Otro error que se le atribuye al sistema de experto, es que considera al razonamiento jurídico como un silogismo; el problema aquí, es, que las premisas del pensamiento judicial, las normas jurídicas y criterios relevantes y la descripción de los hechos decisivos, no se pueden obtener por procedimiento mecánicos. Es innegable que los jueces utilizan una metodología deductiva en sus razonamientos jurídicos para llegar a la norma de decisión, sin embargo, para la elección de las premisas y las reglas de inferencia de su razonamiento, exige una auténtica labor creativa. vid; MARTÍNEZ BAHENA G. C., "La inteligencia artificial y su aplicación al campo del derecho", Op. Cit., pp. 835-836.
} 
de la época actual, es aprender a moldear las bifurcaciones ${ }^{28}$ con las herramientas precisas; por lo tanto, es necesario que desde la política y el derecho exista un replanteamiento sobre los fines del ser humano en la sociedad tecnológica que aún está por redefinirse.

Por otro lado, desde la visión de Hermes, el hombre no es solamente sujeto de derechos, sino además es titular de responsabilidades y deberes para con la sociedad; sin duda todo derecho subjetivo conlleva un deber correspondiente en la persona de otro; no obstante, para Hermes no podemos negar que: "la imaginería jurídica, como el discurso político, han ocultado por mucho tiempo esta realidad, de modo que la insistencia sobre la idea de responsabilidad - ¿para cuándo una Declaración de las Responsabilidades Universales?-conllevaría un profundo trastorno de las mentalidades.” ${ }^{29}$ Para Hermes, el derecho parece estar despojado del peso de aquéllas concepciones de lo justo que implicaban la realización de cualquier idea del bien, de la felicidad social; ${ }^{30}$ actualmente el derecho se concentra en la consecución de lo correcto, en la irreductibilidad de la justicia a la mera legalidad, ${ }^{31}$ o se protege en una microética que impide pensar en soluciones efectivas a los problemas reales de una sociedad fragmentada y desgastada por el abuso del poder, la alta criminalidad, la escasez, corrupción y la impunidad. ${ }^{32}$

Hermes, considera que la naturaleza del derecho debe encontrarse en los hechos, en la experiencia y en el comportamiento de los jueces, de tal forma que vincula la eficacia del derecho con la realidad empírica, como un fenómeno de psicología social, es decir, pretende demostrar que la única realidad que podemos llegar a conocer son los hechos y no otras entidades como los valores, pues considera que estos son metafísica pura al carecer de objetividad. En este sentido, la fuerza ideal y la validez esencial del derecho va a radicar en el grado de obediencia de las normas, de que se cumplan y sean asumidas como vinculantes por la sociedad. Así, Hermes, sostiene la idea de que la coerción (el elemento de la fuerza

${ }^{28}$ Familiarizarse con el nuevo significado de la palabra bifurcación es uno de los conocimientos fundamentales de nuestra época "[...] el significado básico de bifurcación es un súbito cambio de dirección en la manera en que los sistemas se desenvuelven... Las bifurcaciones se desencadenan cuando sistemas complejos están sobretensionados, más allá de su umbral de estabilidad. Hasta ese punto el comportamiento de los sistemas es relativamente ordenado, hay oscilación periódica, es decir movimiento alrededor o hacia determinado estado, o estabilidad en uno u otro estado. Pero más allá del punto crítico, el orden se rompe y el sistema cae en el caos. Su comportamiento ya no es predecible, aunque tampoco es enteramente azaroso. En la mayoría de la clase de sistemas complejos el caos da paso, por último a una nueva variedad de orden... Nosotros mismos y las estructuras ecológicas, sociales, económicas y políticas en que vivimos constituimos sistemas complejos. Estas estructuras se desenvuelven y tarde o temprano sus vías evolutivas se bifurcan. Nuestro mundo está sujeto a súbitos y sorprendentes cambios de fase...”. Vid; LASZLO E., La gran bifurcación. Crisis y oportunidad: anticipación del nuevo paradigma que está tomando forma, Barcelona, ed. Gedisa 1990. Citado por Grün en, "El derecho posmoderno: un sistema lejos del equilibrio”, Op. Cit., p. 170.

${ }^{29}$ OST, F., "Júpiter, Hércules, Hermes: tres modelos de juez”, Op. Cit., p. 128.

${ }^{30}$ Vid; KELSEN, H., ¿Qué es la justicia?, México, Fontamara, trigésima edición, 2016, pp. 8-10.

${ }^{31}$ Vid; ZAGREBELSKY, G., MARTINI, C. M., La exigencia de justicia, Madrid, Minima Trotta, 2006, p. 53. (Trad. Miguel Carbonell).

${ }^{32}$ Vid; SANTOS, B., De la mano de Alicia y lo político en la postmodernidad, Santafé de Bogotá, Siglo de Hombre Editores, 1998, p. 106. (Trad. De C. Bernal y M. García Villegas). 
física), y su uso exclusivo por parte de los jueces, es el único instrumento para lograr su eficacia. La necesidad de la fuerza se referirá al derecho entendido en su conjunto. Desde esta perspectiva realista de Hermes, el derecho tiene un carácter práctico, de modo que la ciencia del derecho deberá de conocerse como tecnología o ciencia social aplicada. ${ }^{33}$

En efecto, la época actual nos obliga a tener una dialéctica basada en la realidad de los hechos y no solo en la ficción de las palabras. El derecho no puede subsumir ante una realidad social ${ }^{34}$ que nos exige normas intersubjetivamente válidas de responsabilidad y deberes para con la sociedad en su conjunto. Desde esta perspectiva, se perciben nuevos peligros, desde el más visto, hasta el más íntimo, lo cual implica tener una capacidad de reacción a gran escala para afrontar, lo que llama Arnaud, la paradoja de las paradojas, ${ }^{35}$ que tiene ver con la incapacidad regulativa del derecho, y su ineficacia a la hora de abordar la complejidad de los fenómenos jurídicos y sociales modernos. ${ }^{36}$

Esta idea de la incapacidad regulativa del derecho para solucionar los problemas que nos muestra la realidad social según Arnaud, se presenta en el contexto mexicano bajo dos supuestos: como problemas de eficacia de los derechos humanos debido a las mínimas posibilidades de realización práctica; y como problemas de legitimación social del sistema de justicia penal y de seguridad en México, originado por la falta de efectividad de los mecanismos y fundamentos con lo que opera para cumplir con la finalidad de reducir a límites razonables la criminalidad, y por los efectos sociales creados, como la predictibilidad de la vigencia jurídica, inseguridad pública e impunidad; hechos que pos sí mismos generan problemas de imputación, un daño a las víctimas de los delitos, y por ende, un deterioro en la confianza de los ciudadanos en el sistema jurídico.

33 Vid; ATIENZA, M., El sentido del derecho, Barcelona, ed. Ariel, 2013, pp. 294-295. También vid; FASSÓ, G., Historia de la Filosofía del Derecho 3. Siglos XIX y XX, Madrid, Ediciones Pirámide, 1996, p.240. (Traducción de José F. Lorca Navarrete). Citado por: HALLIVIS PELAYO, M., Teoría general de la interpretación, México, D.F., ed. Porrúa, 2012, p. 180. También vid; BARBERIS, M., "El Realismo Jurídico Europeo-Continental”, en, ZAMORA FABRA, J.L., / NÚÑEZ VAQUERO, Á., (Eds.), Enciclopedia de filosofía y teoría del derecho, Vol. I, México, IIJ-UNAM, 2015, pp. 228-229.

${ }^{34}$ Bajo este contexto se entenderá por realidad social, “un sistema de creencias, representaciones, pensamientos, sentimientos, actitudes y conductas compartidas por los miembros de una sociedad dada”. Vid: CÁCERES NIETO, E., Institucionalismo jurídico y constructivismo social, Boletín Mexicano de Derecho Comparado, nueva serie, año XXXIV, núm. 100, enero-abril de 2001, p. 15.

${ }^{35}$ La presencia de paradojas y contradicciones en la teoría y práctica de los derechos humanos no debe resultar extraña, pues estas se dan dentro de la relaciones entre los hombres y se proyectan en las dimensiones de la moral y del derecho. Así para López Calera, los derechos humanos tienen una naturaleza dialéctica: "Hágase lo que se haga, piénsese lo que se piense, el mundo de los derechos humanos es un mundo lleno de contradicciones”, “[...] los derechos humanos no son una realidad fija, estática, que pueda ser comprendida y mucho menos determinada por la praxis de manera objetiva y definitiva, sino que son una realidad que fluye en medio de contradicciones". Vid; LÓPEZ CALERA, N. M., "Naturaleza dialéctica de los derechos humanos”, Anuario de Derechos Humanos, n 6, 1990, pp. 73-75.

${ }^{36}$ ARNAUD, A. J., “Los juristas frente a la sociedad (1975-1993)”, Doxa, n 15-16, 1994, p. 1003. (Trad. I. Lifante y V. Roca), 
En este sentido, para entender los problemas de legitimación social que presenta el nuevo sistema de justicia penal en México, y ubicar el punto crítico de Hermes al funcionalismo penal moderado, es preciso señalar brevemente, que con el impacto de las reformas de justicia penal de 2008, la condena de la Corte Interamericana de Derechos Humanos, (en adelante CoIDH) al Estado Mexicano con el caso Radilla Pacheco de $2009^{37}$, y la reforma constitucional en materia de derechos humanos de $2011,{ }^{38}$ se ha originado un nuevo paradigma en la forma de interpretar y aplicar el derecho, impartir justicia y ejercer el poder público. En lo que respecta al nuevo modelo de justicia penal y de seguridad, es importante destacar que se debió a varios factores, por ejemplo, podemos mencionar la necesidad del Estado mexicano de dar cumplimiento a los compromisos adquiridos en los tratados internacionales, y en las Observaciones emitidas por los mecanismos de Naciones Unidas en materia de justicia, así como el rezago que presentaba el Estado mexicano en comparación con otros países de Latinoamérica en la modernización del sistema de justicia penal. $^{39}$

Otros factores fundamentales que propiciaron las reformas, se debieron a la ineficacia de un aparato de justicia que había perdido toda su credibilidad en su función de proteger los derechos humanos y garantías, y en proporcionar seguridad pública. En este sentido, los principales argumentos del Estado se basaban en el hecho de que la delincuencia organizada representaba una seria amenaza para el Estado y la sociedad; era evidente la penetración de los grupos criminales en las instituciones públicas, la creciente impunidad que impedía una justicia y reparación del daño para las víctimas, pues de cada 100 delitos que se denunciaban en México, solo cinco recibían sentencia; situación, que según el Estado, se debía al poder económico y en la capacidad de la criminalidad organizada para operar deliberadamente en evadir la justicia. Además, era innegable la opacidad y la burocracia engorrosa de los procesos y juicios penales, así como la desconfianza en el sistema penitenciario de garantizar la reinserción social a causa de la inseguridad y corrupción en las cárceles, generando los espacios para que se perfeccionaran las habilidades delincuenciales como si fueran universidades del crimen. En definitiva, estas situaciones, entre otras más, llevaron a la conclusión de que el sistema de justicia penal resultaba un sistema injusto, arcaico e ineficaz, y que por lo tanto, debería cambiarse por un modelo moderno basado en el common law. En este contexto, el Estado mexicano inicia los

\footnotetext{
${ }^{37}$ CoIDH, Caso Radilla Pacheco versus Estados Unidos Mexicanos, Sentencia sobre el fondo, del 23 de noviembre de 2009.

${ }^{38}$ Sobre un análisis completo de la reforma constitucional de derechos humanos vid; CARBONELL M., /SALAZAR, P., La reforma constitucional de derechos humanos: un nuevo paradigma, México, D.F., ed. Porrúa, IIJ-UNAM, 2011.

${ }^{39}$ Vid; LUNA CASTRO, J. N., "Introducción y características generales del nuevo Sistema de Justicia Penal”, en, AA.VV. El nuevo Sistema de Justicia Penal Acusatorio, dese la perspectiva constitucional, México, Consejo de la Judicatura Federal, $1^{\text {a }}$ ed. 2011, p. 34.
} 
trabajos para reformar diez artículos de la Constitución mexicana que transformará desde su núcleo esencial el sistema de justicia penal y de seguridad en México. ${ }^{40}$

No obstante, a pesar de que desde el 18 de junio de 2008 ha habido una intensa labor ardua y uniforme para dar cumplimiento a la reforma penal constitucional, y que desde el 18 de junio de 2016 ya tiene plena vigencia el sistema penal acusatorio en todo el país, el contexto impulsor de la reforma no ha cambiado del todo. Paralelamente se presentan en la actualidad algunas tensiones generadas desde el inicio de la aludida reforma, por la decisión de vincular simultáneamente los aspectos político-criminales, junto con los fundamentos de un sistema penal acusatorio híper garantista. ${ }^{41}$ Este conflicto creó una tensión dialéctica entre una lógica punitiva y de control mediante la implementación de restricciones o categorías de excepción diseñadas para combatir los efectos de la criminalidad organizada, y los principios y fundamentos con los que opera el sistema penal acusatorio orientado principalmente a maximizar el respeto de los derechos humanos y garantías en los procesos penales. $^{42}$ De tal manera que frente a la complejidad creciente de la violencia y la criminalidad, el sistema de justicia penal parece hallarse en estado lejos del equilibrio, entre la no impunidad -el castigo a los culpables- y la protección de los derechos humanos del más débil, -la víctima del delito-. Situación que ha generado un descontento en la ciudadanía afectada por la repercusión de las conductas delictivas en sus proyectos de vida, y una crisis de confianza en el justiciable, que se traduce a fin de cuentas, en problemas de legitimación social de este nuevo paradigma de justicia panal en México. ${ }^{43}$ 40 Sobre la reforma constitucional de seguridad y justicia en México vid;
http://portal.setec.gob.mx/docs/guia.pdf

${ }^{41}$ Sobre el estado actual del sistema penal acusatorio en México, vid; COSSÍO DÍAZ, J. R., https://www.youtube.com/watch?v=UImpf33g2g4

${ }_{42}$ Para una mayor comprensión de la reforma penal y el sistema penal acusatorio en México, vid; GÓMEZ GONZÁLEZ, A., Reforma penal 2008-2016. El Sistema Penal Acusatorio en México, Ciudad de México, INACIPE, $1^{\text {a }}$ ed. 2016, pp. 1-1046.

${ }^{43}$ Es preciso mencionar que según la Encuesta Nacional de Victimización y Percepción sobre Seguridad Pública (en adelante ENVIPE), estima que en México existen 23.3 millones de víctimas de 18 años y más, lo cual representa una tasa de prevalencia delictiva de 28,202 víctimas por cada cien mil habitantes durante 2015. La percepción de inseguridad de la población de 18 años y más, en las entidades federativas al momento del levantamiento de la encuesta (marzo-abril 2016), se ubicó en 72.4\%. Otro indicador importante señala que a nivel nacional el 59.1\% de la población de 18 años y más considera la inseguridad y delincuencia como el problema más importante que afecta en la actualidad en su entidad federativa, seguido del desempleo con $40.8 \%$ y la pobreza con $31.9 \%$. La ENVIPE, estima que en 2015 se denunció el 10.5\% del total de los delitos, y para los cuales el Ministerio Público inició averiguación previa o carpeta de investigación en 59.6\% de los casos. Durante 2015 se inició averiguación previa en el 6.3\% del total de los delitos. Lo anterior, representa un 93.7\% de delitos donde NO hubo denuncia o NO se inició averiguación previa. En este sentido, la ENVIPE permite estimar que la "Cifra Negra" a nivel nacional en 2015 fue de $93.7 \%$ lo que implica un incremento respecto de la estimación de $92.8 \%$ en 2014. Del total de averiguaciones previas iniciadas por el Ministerio Público, en el $45.9 \%$ de los casos no pasó nada o no se resolvió la denuncia. Los principales motivos que llevan a la población víctima de un delito a no denunciar son circunstancias atribuibles a la autoridad, tales como considerar la denuncia como pérdida de tiempo con $33 \%$ y la desconfianza en la autoridad con $16.6 \%$. La encuesta contiene información sobre el tipo de delitos que afectan de manera directa 
Este escenario ha motivado una serie de posiciones controversiales en varios ámbitos de la sociedad mexicana relativos a las funciones, mecanismos y fundamentos con los que debe operar la justicia penal para afrontar situaciones relacionadas con la criminalidad organizada, la violencia extrema, impunidad, reducción de la inseguridad y un mejor control del orden social por parte del Estado en temas de justicia penal y seguridad. ${ }^{44}$ En este sentido, tenemos una argumentación de política criminal basada en la presunción de inocencia, y en la dignidad de la persona en su función con el grupo social; y por otro lado, un modelo para criminalizar sustentado en la presunción de culpabilidad, en derechos acotados y garantías mínimas procesales para el imputado. Por lo tanto, teorizar, será fundamental en esta materia, de modo que, de entre toda la dogmática penal, expondremos brevemente, dos tipos de funcionalismo penal: el funcionalismo penal valorativo y el funcionalismo penal normativo riguroso, o radical; modelos cuyo estudio y análisis resultan necesarios para tener mejores lógicas efectivas y una visión más amplia sobre el modo de afrontar la realidad de un nuevo orden criminal más sofisticado e inhumano, el fenómeno de la criminalidad posmoderna. ${ }^{45}$

En primer lugar, presentamos la tesis del funcionalismo penal valorativo o moderado sustentando por Claus Roxin, quien sostiene que para combatir la criminalidad debe estar basada en una estrategia nacional de prevención interdisciplinaria y de respeto a los derechos fundamentales orientada a la búsqueda de alternativas al castigo penal, es decir, el sistema de penas debe limitar en lo posible los comportamientos delictivos con la amenaza penal. Desde esta concepción la persona acusada de violar una norma solo responde por la lesión del valor tutelado, por lo tanto, la pena adquiere una función de reinserción, de reparación del daño social como prevención general positiva, de una reeducación del criminal y no de privación de su libertad, excepto de delitos especialmente graves. ${ }^{46}$

a las víctimas o a los hogares, tales como: robo total de vehículo, robo parcial de vehículo, robo en casa habitación, robo o asalto en calle o transporte público, robo en forma distinta a las anteriores (como carterismo, allanamientos, abigeato y otros tipos de robo), fraude, extorsión, amenazas verbales, lesiones y otros delitos distintos a los anteriores (como secuestros, delitos sexuales y otros delitos). Como consecuencia, el gasto de los hogares en medidas para protegerse de la delincuencia en 2015 tuvo un incremento de $17.7 \%$ respecto del estimado en 2014. (Subrayado añadido).

Las estadísticas que se presentan nos indican la desconfianza de la ciudadanía en el sistema de procuración de justicia en nuestro país, en ese sentido, tenemos un reto mayor: restaurar el tejido social a través del fortalecimiento del sistema de justicia penal y seguridad en México. Los resultados completos de la encuesta consúltense aquí: http://www.inegi.org.mx/saladeprensa/boletines/2016/especiales/especiales2016_09_04.pdf

44 Vid; CARLOS ESPINOSA, A., "Criminología de la posmodernidad. Una lectura de derecho penal regional”, en, AA.VV. Entre libertad y castigo: dilemas del estado contemporáneo, México, IIJ-UNAM, Facultad de Derecho, $1^{\text {a }}$ ed., 2011, pp. 168-169

45 Para un mayor entendimiento del derecho penal posmoderno, vid; PARMA C., Derecho penal posmoderno, Perú, Ara editores, 2005.

${ }^{46}$ Vid; ROXIN, C., “Zur Kriminalpolitischen Fundierung des Strafrechtssystems”, em Festschrift für Günther Kaiser, Berlin, Duncker \& Humblot, 1998, pp. 885 y ss. Citado por: ARIAS EIBE, M. J., "Funcionalismo penal moderado o teleológico-valorativo versus funcionalismo normativo o radical”, Doxa, Cuadernos de Filosofía del Derecho, n² 29, 2006, pp. 440-442. 
En base a este funcionalismo penal, en los últimos años en México se han realizado fuertes críticas en contra de la figura del arraigo ${ }^{47}$ como medida precautoria para combatir la delincuencia organizada. Los señalamientos se centran en que esta medida precondenatoria sitúa a la persona en un estado de indefensión al suspenderse sus derechos de manera temporal, afectando su plan de vida, restringiendo sus derechos de libertad e integridad personales, el principio de presunción de inocencia y el debido proceso, además que la pone en riesgo de ser víctima de tortura y otros tratos crueles, inhumanos y degradantes ${ }^{48}$ Por consiguiente, desde esta posición axiológica, ven un vínculo estrecho entre la concepción del valor absoluto de los derechos humanos y garantías y los “intereses críticos”, es decir, que el valor del criminal como persona es independiente de su historia particular, la clase de delitos que comete, del nivel de crueldad de sus actos, o de la impresión que generen en la sociedad; es decir, el carácter intrínseco de sus derechos y de su dignidad, no se ven afectados, ni dependen de la percepción del daño ocasionado a la víctima o al bienestar de la comunidad. ${ }^{49}$

En segundo lugar, tenemos, el funcionalismo penal normativo radical, que va a tratar de superar lo abstracto del funcionalismo penal axiológico adoptando una postura rigurosa para lograr la estabilización social. Desde esta concepción el sujeto aparece como un peligro para el Estado y la sociedad. Por lo tanto, aparece un derecho penal de excepción

\footnotetext{
${ }^{47}$ En el año 2008 el arraigo como "medida precautoria” se introduce en la Constitución mexicana bajo el argumento de su necesidad para evitar que el imputado pueda evadirse de las autoridades, o bien, que pueda obstaculizar el éxito de las investigaciones cuando se trate única y exclusivamente para delitos de delincuencia organizada, permitiendo de esta manera restringir la libertad personal bajo ciertos requerimientos señalados en el texto del artículo 16, párrafo octavo que sobre el particular señala que: “(...) La autoridad judicial, a petición del Ministerio Público y tratándose de delitos de delincuencia organizada, podrá decretar el arraigo de una persona, con las modalidades de lugar y tiempo que la ley señale, sin que pueda exceder de cuarenta días, siempre que sea necesario para el éxito de la investigación, la protección de personas o bienes jurídicos, o cuando exista riesgo fundado de que el inculpado se sustraiga a la acción de la justicia. Este plazo podrá prorrogarse, siempre y cuando el Ministerio Público acredite que subsisten las causas que le dieron origen. En todo caso, la duración total del arraigo no podrá exceder los ochenta días". Sobre los diversos puntos de vista del arraigo, Vid; LARA RIVERA, J. A., "La figura del arraigo es pertinente y cumple cabalmente criterios de derechos humanos", Defensor, Revista de Derechos Humanos, CDHDF, N 02, año X, febrero 2012, pp. 8-12.

${ }^{48}$ Las violaciones sistemáticas a los derechos humanos relacionadas con el uso del arraigo, ha dado lugar a que varios organismos internacionales realicen señalamientos y recomendaciones destinadas a condenar esta práctica a nivel federal y local. Vid; Grupo de Trabajo sobre Detenciones Arbitrarias, 2002, párr. 50; Comité Contra la Tortura, 2007, párr. 15; Subcomité de Prevención de la Tortura, 2009, párr. 238; Consejo de Derechos Humanos, Examen Periódico Universal, 2009; Comité de Derechos Humanos, 2010, párr. 15; Relatora Especial de la ONU sobre la Independencia de Jueces y Abogados, 2010, párr. 92-94; Grupo de Trabajo sobre Desapariciones Forzadas o Involuntarias, 2011, párr. 88; Comité Contra la Tortura, 2012, párr. 11. También vid; Recomendación 2/2011. Caso de violaciones a derechos humanos con motivo de la solicitud, expedición y condiciones en las que se aplica el arraigo en el Distrito Federal. Comisión de Derechos Humanos del Distrito Federal.

${ }^{49}$ Vid; DWORKIN, R., El dominio de la vida, Barcelona, Ariel, 1996, pp. 306 y ss. (Trad. Ricardo Caracciolo y Víctor Ferreres). También vid; PÉREZ TRIVIÑO, J. L., De la dignidad humana y otras cuestiones jurídicomorales, México, D.F., Fontamara, $1^{\mathrm{a}}$ ed. 2007.
} 
cuya finalidad es combatir esos peligros a través de ciertas medidas de seguridad como la restricción de determinados derechos humanos. ${ }^{50}$ Bajo este argumento, los derechos humanos estarán supeditados por un conjunto de expectativas de comportamiento sostenidas por el consenso, y que operan en el sistema social como filtros y límites frente a la tendencia expansiva del Estado. ${ }^{51}$ De tal manera que si no se garantizan las expectativas normativas y sociales de comportamiento, se podrán restringir los derechos humanos a través de un derecho que sirva como instrumento de cohesión social. ${ }^{52}$

En el centro de esta teoría penal encontramos a Günther Jakobs, considerado como uno de los juristas más polémicos, artífice del llamado "derecho penal del enemigo". Jakobs se basa en la cualidad del sujeto que defrauda la expectativa normativa, modificando la estructura de la culpabilidad y la pena, en el supuesto del “enemigo”. Para Jakobs, la función de la pena no es la coacción dirigida contra la persona, sino la de combatir el riesgo generado por el sujeto peligroso a través de medidas de seguridad. ${ }^{53}$ En efecto, lo fundamental de esta teoría se concentrará en la eficacia de la pena en relación a la reafirmación de la validez de la norma y el restablecimiento del orden social. ${ }^{54} \mathrm{Jakobs}$ considera que "quien no presta una seguridad cognitiva suficiente de un comportamiento personal, no solo no puede esperar ser tratado aún como una persona, sino que el Estado no debe ya tratarlo como persona, ya que de lo contrario vulneraría el derecho a la seguridad de las demás personas”. ${ }^{55}$ Por lo tanto, la persona existe en función de su relación social en base no solo a la autodeterminación personal, sino que se define mediante una regla independiente de cualquier decisión o preferencia, pudiendo ser invocada por los demás. Esta regla se convierte para Jakobs en una norma social en sentido estricto: en el momento en que nos damos cuenta lo que queremos para nosotros, es decir, que no se nos haga nada malo, que pueda considerarse como algo cruel, inhumano, injusto, es válido también para los demás. En este sentido, en Jakobs se resalta la importancia en la formación de "todo orden personal," de los “deberes de contribuir al mantenimiento del grupo que existe a través del orden”. 56

\footnotetext{
50 Sobre la justificación de nuevos paradigmas penales, vid; PORTILLA CONTRERAS, G., (Coord.) Mutaciones de Leviatán. Legitimación de los nuevos modelos penales, Andalucía, España, ed. AKAL, 2005.

${ }^{51}$ Vid; PRIETO NAVARRO, E., "La teoría de sistemas de Luhmann y el derecho", en, GARCÍA AMADO, J. A., (Coord.), El derecho en la teoría social. Diálogo con catorce propuestas actuales, Madrid, Ed. Dykinson, 2001, p.340. También vid; JAKOBS, G., Derecho Penal. Parte General. Fundamentos y teoría de la imputación, Madrid, Civitas, 2a ed., 1997, p. 12.

${ }^{52}$ MONTORO BALLESTEROS, A., "El funcionalismo en el Derecho: notas sobre N. Luhmann y G. Jakobs”, Anuario de Derechos Humanos. Nueva Época. Vol. 8, 2007, p. 370,

${ }^{53}$ Vid; JAKOBS, G., "Derecho penal del ciudadano y Derecho penal del enemigo”, Op. Cit., pp. 24-25.

${ }^{54}$ Vid; ARIAS EIBE, M. J., "Funcionalismo penal moderado o teleológico-valorativo versus funcionalismo normativo o radical”, Op. Cit., pp. 447.448.

55 JAKOBS, G., "Derecho penal del ciudadano y Derecho penal del enemigo", en, Derecho penal del enemigo, Madrid, Cuadernos Civitas, 2003, p. 47. (Trad., de M. Cancio Meliá).

${ }^{56}$ JAKOBS, G., "Sobre la génesis de la obligación jurídica”, Doxa, n 23, 2000, pp. 342-343. (Trad., de M. Cancio Meliá). Del mismo autor vid; Sociedad, norma y persona en una teoría de un derecho penal funcional, Madrid, Civitas, 1996, p. 79. (Trad., de M. Cancio Meliá y B. Feijóo Sánchez).
} 
A pesar de tener una mayor aceptación el funcionalismo penal axiológico, las teorías del funcionalismo penal radical o estratégico han venido cobrando cierta aceptación en el ámbito de la dogmática penal mexicana; ${ }^{57}$ constitucionalmente lo tenemos en figuras como el arraigo, en diversas disposiciones del derecho penal y en recientes resoluciones de la Suprema Corte de Justicia de la Nación, (en adelante SCJN). ${ }^{58}$ Este acercamiento apunta hacia una posición penal restrictiva para reducir la alta peligrosidad que representa el crimen organizado para la sociedad, y que no se ha podido solucionar con la política criminal y con las reglas del sistema penal acusatorio actual.

En este sentido, desde la concepción crítica de Hermes al funcionalismo penal axiológico, se plantea la posibilidad de que: en un contexto, en el que predomine la inseguridad pública, violencia extrema, actos de terrorismo, y alta criminalidad, se pueda tener una posición más rigurosa y radical en el derecho penal, que logre ser factible, que en un proceso judicial, una persona o un grupo de personas que cometan actos orientados a la destrucción del tejido social, y que conmocionen la seguridad del estado, se les pueda juzgar con las máximas del derecho penal, ya sea desde una construcción normativa, que anteponga restricciones punitivas modificando la estructura de la culpabilidad y la pena, es decir, ajustando los criterios de imputación de responsabilidad penal para contener la realización de conductas criminales; o a través de evidencia científica, obtenida de la

\footnotetext{
${ }^{57}$ Sobre las implicaciones del "derecho penal den enemigo" en el sistema de justicia penal en México, vid; UROSA RAMÍREZ, G. A., "Algunas reflexiones en relación con el "derecho penal del enemigo" dentro del contexto nacional”, Revista de la Facultad de Derecho de México, vol. 61, n 255, UNAM, 2011, pp. 71-92.

${ }^{58}$ Como parte de esta concepción del funcionalismo penal riguroso o radical en el que se privilegia el enfoque de la "peligrosidad" del criminal desde una "construcción normativa”, lo podemos ver claramente, como habíamos visto ut supra-, con la figura del "arraigo"; que, al introducirse en la constitución mexicana esta medida precautoria destinada a evitar que el imputado se sustraiga de la justicia, obstaculice las investigaciones o pueda ponerse en riesgo a las víctimas de los delitos, permite que se justifique la restricción legítima a los derechos humanos como la libertad personal y la presunción de inocencia. Un aspecto fundamental, es que, a raíz de la resolución de la contradicción de tesis 293/2011 de la SCJN, deja sin validez cualquier contenido normativo reconocido en un tratado internacional o los criterios de interpretación que resulten de ellos cuando se confronten con la existencia de restricciones expresas al ejercicio de los derechos humanos en la Constitución como el caso del "arraigo". Por lo tanto, bajo este criterio de la SCJN, deja sin efecto todo recurso judicial que pueda interponerse o técnica de interpretación judicial que pueda aplicarse en contra de esta medida precautoria así transgreda principios y derechos humanos reconocidos en el artículo $1^{\circ}$ de la Constitución mexicana que conllevan una serie de mandatos de actuación y de optimización del sistema jurídico. Sobre la Contradicción de tesis 293/2011 SCJN, Gaceta del Semanario Judicial de la Federación, Libro 5, Abril de 2014, Tomo I, p. 96. El 14 abril de 2015 la SCJN en base a la resolución del amparo directo en revisión 1250/2010 amplía la aplicación de esta medida precautoria para “delitos graves” hasta por 40 días, al declarar la constitucionalidad del artículo 133 bis del Código Federal de Procedimientos, y el artículo 11 transitorio del decreto de reforma constitucional en materia penal de junio de 2008.A pesar de que el arraigo para delitos graves solo tendría vigencia en tanto entrase en vigor el Sistema Penal Acusatorio en todo el país, no deja de ser un precedente importante de la SCJN que nos indica una postura funcional penal restrictiva de los derechos humanos. Sobre los argumentos de los ministros en torno a la figura del arraigo vid; https://www.sitios.scjn.gob.mx/video/?q=video/1712
} 
aplicación de “dictámenes neuropsicológicos” y de “predicción de riesgo" 59 que puedan ser aprovechados como instrumentos de valoración para medir la capacidad cognitiva del comportamiento criminal, la alta peligrosidad, y el riesgo de violencia, para poder tomar las medidas restrictivas ${ }^{60} \mathrm{y}$ de protección a los derechos de las víctimas de los delitos. ${ }^{61}$

En definitiva, desde este funcionalismo penal radical, al establecerse la predictibilidad conductiva criminal contraria a los intereses de experiencia del Estado y del grupo social, las penas y las medidas restrictivas que se impongan, dependerán principalmente de que se pueda garantizar una capacidad cognitiva suficiente de un comportamiento que pueda causar un daño o poner en riesgo la seguridad de los demás. ${ }^{62}$ En definitiva para Hermes, lo que se pretende con estos criterios, es demostrar mayor grado de eficacia preventiva en la comisión de delitos cometidos por criminales de alta peligrosidad, logrando en consecuencia, una estabilización del Estado de derecho, del orden, y la paz social. ${ }^{63}$

\section{DERECHOS HUMANOS Y POSMODERNIDAD: NUEVOS RASGOS Y CONCEPCIONES EN EL PARADIGMA CONSTITUCIONAL}

\footnotetext{
${ }^{59}$ Sobre la aplicación práctica de dictámenes basados en estudios neuropsicológicos y de predicción de riesgo en el sistema judicial mexicano, vid; DZIB AGUILAR, J. P., Manual Práctico de Psicología Forense, Mérida, Yuc., México, Universidad Autónoma de Yucatán, 2013.

${ }^{60}$ Esta posición del Juez Hermes en relación a la evidencia judicial basada en estudios neuropsicológicos y de predicción de riesgo, podría aplicarse en nuestro proceso penal mexicano, una vez que la unidad de medidas cautelares encargada de emitir dictámenes de riesgo personalizados del imputado o vinculado, presente la evidencia aportada por las autoridades competentes, en la que se haya podido medir la capacidad cognitiva y valorar la peligrosidad y el riesgo de violencia del criminal, el juez podrá justificar racionalmente basándose en la experiencia científica y no intuitiva, la estricta necesidad de las restricciones a los derechos humanos y garantías en delincuentes violentos o con un perfil de alta criminalidad; que, a su vez, podría perfeccionarse como medio de prueba en la etapa intermedia, a fin de que en la audiencia de individualización de sanciones y medidas de seguridad, se desahogue como prueba la experticia de los especialistas a fin de orientar al juez en su decisión de determinar el grado de culpabilidad, imponer la medida restrictiva, y a su vez el quantum de la pena, persiguiendo los fines de no reincidencia y reinserción social junto con el tratamiento interinstitucional e interdisciplinario para hacer eficaces los principios del sistema penal acusatorio. Vid; RODRÍGUEZ ZURITA, F., El grado de culpabilidad: directrices para lograr la eficacia en el nuevo Sistema Penal Acusatorio en México, Ponencia inédita, México, 2017. Jueza del Tribunal Primero de Enjuiciamiento del Estado de Yucatán (México).

${ }^{61}$ Actualmente hay estudios derivados de investigaciones neuro científicas sobre las conductas antisociales y psicopáticas que señalan los alcances esenciales de las amígdalas cerebrales en las conductas delictivas. Está científicamente comprobado, que, cuando se daña o se ve afectada estructuralmente la corteza pre frontal, que es la zona donde reside la sede del razonamiento moral y lo instintos primarios-, se tendrá mayor predisposición hacia la realización de conductas violentas o estrictamente criminales. Vid; DAMASIO, R. A., El error de Descartes, Barcelona, ed. Andrés Bello, 1996, pp. 73-103. (Trad. Pierre Jacomet).

${ }^{62}$ Vid; DWORKIN, R., El dominio de la vida, Op Cit., p. 306 y ss.

${ }^{63}$ Sobre los retos que plantea el derecho penal en la actualidad vid; MACEDONIO, HERNÁNDEZ, C., A., "La acción privada de la víctima en el proceso penal acusatorio del Estado de Yucatán ¿el retorno a una acción procesal ineficaz o verdadero beneficio para la víctima?”, en, GORJÓN GÓMEZ, F. J., (Coord.) Mediación Penal y Justicia Restaurativa, México, Tirant lo Blanch, 1ª ed. 2014, pp. 231-259.
} 
Con la aparición de la teoría del constitucionalismo contemporáneo, la nueva dogmática jurídica relacionada con la argumentación, la interpretación, el garantismo y el no positivismo principialista ${ }^{64}$, ha ocasionado, que el derecho, tanto en la práctica como en la teoría, apunte hacia una nueva perspectiva lejos de la teoría tradicional positivista que por tanto tiempo rigió nuestra manera de entender y aplicar el derecho. Esta transición jurídica ha puesto a los derechos humanos como el eje central de la ingeniería constitucional, originando un cambio en los métodos para estudiar los sistemas jurídicos contemporáneos. ${ }^{65}$ Con este cambio de paradigma constitucional en México, los derechos humanos empiezan a adquirir nuevos rasgos definitorios que vienen a formar parte de un derecho posmoderno $^{66}$ caracterizado por su alta complejidad, por una multiplicidad de datos, ${ }^{67}$ por un derecho intersticial que origina una nueva forma de entender la validez constitucional de los derechos.

\section{III.1. La multiplicidad de estándares normativos}

La multiplicidad del derecho del constitucionalismo posmoderno empieza a vislumbrarse en México, a raíz de la reforma constitucional en materia de derechos humanos del 10 de junio del 2011; reforma de mayor alcance y relevancia que ha experimentado nuestra Carta Magna desde el inicio de su vigencia; más específicamente a la reforma del artículo primero de la Constitución, en lo que se refiere al impacto, el efecto impregnación o irradiación ${ }^{68}$ que los valores, principios, objetivos políticos, directrices,

\footnotetext{
${ }^{64}$ Zagrebelsky en el capítulo sexto de su obra el derecho dúctil, se apega desde el derecho constitucional a una doctrina caracterizada por dos aspectos fundamentales, primero: la censura del positivismo jurídico y segundo: la aplicación de los principios como instrumentos de tal intervención. Esta teoría es la que se |denomina como el no positivismo principialista. La cual expresa que: si existen principios en el derecho, evidentemente es imposible una concepción positivista del derecho. Para un mayor entendimiento, por positivismo jurídico se concebirá, a la teoría que sostiene la ausencia de una relación conceptual necesaria entre derecho y moral; y, por no positivismo la que se fundamenta sobre la tesis contraria, es decir, la existencia de una conexión conceptual ineludible entre derecho y moral. Por consiguiente, el rasgo principialista se referirá a la unidad de recurrir a los principios para explicar las insuficiencias del modelo positivista del derecho. ${ }^{64}$ Sobre las implicaciones del no positivismo principialista en la teoría de Zagrebelsky, vid; GARCÍA FIGUEROA, A., "El no positivismo principialista en Il diritto mite de Gustavo Zagrebelsky”, Anuario de Filosofía del Derecho XIII, (1996), pp. 87-109.

${ }^{65}$ Vid; SALAZAR UGARTE, P., "Garantismo y neoconstitucionalismo frente a frente: algunas claves para su distinción”, Doxa, Cuadernos de Filosofía del Derecho, n 34, 2011, p. 298.

${ }^{66}$ El derecho posmoderno es, sin lugar a dudas, un sistema altamente complejo, sea que se considere al sistema jurídico de una nación, de una región o al de derecho internacional. Vid; GRÜN, E., "El derecho posmoderno: un sistema lejos del equilibrio”, Op. Cit., pp. 16-25.

${ }^{67}$ Sobre la multiplicidad como característica del derecho posmoderno, vid; GARCÍA INDA, A., "Cinco apuntes sobre Derecho y postmodernidad”, Doxa, Cuadernos de Filosofía el Derecho, n 24, 1989, pp. 11-14.

${ }^{68}$ El "efecto irradiación" (Ausstrahlungswirkung) suele aludir en la doctrina alemana a la eficacia o proyección de los derechos fundamentales en el ámbito del Derecho privado. Aquí se usa en un sentido más general. Al respecto, Vid; PRIETO SANCHÍS, L., Justicia constitucional y derechos fundamentales, Madrid, Trotta, 2003, p. 119.
} 
jurisprudencias y tratados internacionales tienen sobre el conjunto del sistema jurídico; esto último, efecto de lo que Prieto Sanchís denomina una "rematerialización constitucional”"69 como rango definitorio del constitucionalismo de nuestra época. ${ }^{70}$

Esta remisión normativa que permite incorporar los derechos humanos de fuente internacional al catálogo de derechos humanos de la constitución, crea lo que se conoce como el "bloque de constitucionalidad", ${ }^{71}$ el cual cumple una función trascendental no solo

${ }^{69}$ Este enfoque de rematerialización del derecho constitucional tiene su origen en la primera jurisprudencia del Tribunal Constitucional Federal Alemán; específicamente, en la sentencia Lüth, de 1958, en la que se establecen conceptos como: valor, ordenamiento valorativo, jerarquía valorativa y sistemas de valores, en los que se apoyará posteriormente el Tribunal en numerosas decisiones. La importancia de esta sentencia radica en su consideración como norma objetiva, los principios y la decisión axiológica de los denominados "derechos fundamentales", que pasan de esta manera a informa a todo el sistema jurídico, operando como principio hermenéutico. Vid; CRUZ, L. M., La Constitución como orden de valores. Problemas jurídicos y políticos, Granada, España, Editorial Comares, 2005, pp. 9-16. "Este conocidísimo caso versaba sobre un pleito entre el director de cine Veit Harlan y Lüth, el presidente de la oficina de prensa de Hamburgo. En diversas oportunidades, éste había atacado públicamente a Harlan, quien anteriormente había dirigido judío dulce, una película de propaganda antisemita, y que ahora presentaba al público y a las empresas cinematográficas a boicotear la nueva película. Los tribunales de primera y segunda instancia consideraron que la conducta del periodista vulneraba las buenas costumbres del $£ 826$ del Código Civil. Por el contrario, la Corte Constitucional Federal concedió la tutela interpuesta por este último, al considerar que su conducta era un ejercicio legítimo de la libertad de expresión y que esta libertad también se aplicaba en el ámbito del derecho civil”. ALEXY, R., Tres escritos sobre los derechos fundamentales y la teoría de los principios, Colombia, Universidad Externado de Colombia, Serie de Teoría Jurídica y Filosofía del Derechos, $\mathrm{N}^{\circ}$ 28, 2003, p. 43. (Trad. Carlos Bernal Pulido). Véase extracto de la sentencia BVerfGE 7, 198 [Lüth], en, SCHWABE J., (Coomp.), Jurisprudencia del Tribunal Constitucional Federal Alemán. Extractos de las sentencias más relevantes, México, D.F., Konrad-Adenauer-Stiftung, 2009, p. 202.

${ }^{70}$ Vid PRIETO SANCHÍS, L., Justicia constitucional y derechos fundamentales, Op. Cit., p, 101 y ss. También vid; PRIETO SANCHÍS, .L., "El Constitucionalismo de los derechos”, en, CARBONELL, M., (Editor), Teoría del Neoconstitucionalismo, México. Trotta-UNAM, 2007.

${ }^{71}$ El concepto de "Bloque de Constitucionalidad" proviene de Francia, donde fue desarrollado a partir de la década de los setenta. Se entiende como el conjunto de principios y reglas de valor constitucional para designar el conjunto de normas situadas a nivel constitucional, cuyo respeto se impone a la ley. Vid; FAVOREU, L., El Bloque de Constitucionalidad”, Revista del Centro de Estudios Constitucionales, Madrid, $\mathrm{N}^{\circ}$ 5. Enero-marzo 1990, pp. 45-68. Posteriormente, el "Bloque de constitucionalidad" como figura jurídica se desarrolló ampliamente por la jurisprudencia constitucional comparada cumpliendo una función trascendental no solo teórica sino práctica, en la medida en que permite incorporar los estándares normativos del derecho internacional de los derechos humanos al ordenamiento jurídico mexicano. Es decir, el control de constitucionalidad deberá emplearse no solo frente las disposiciones de la Constitución, sino también a partir de su confrontación con otros dispositivos de carácter supraconstitucional, como los criterios jurisprudenciales, las normas y principios que sin estar formalmente incluidos en la constitución, son utilizados como parámetros de validez de control de constitucionalidad.Vid; MORALES MORALES. A. V., ODIMBA ON'ETAMBALAKO WETSHOKONDA, J. C. "La incorporación del concepto de bloque de constitucionalidad en materia de derechos humanos en México", Prolegómenos. Derechos y Valores, 2011; IV, pp. 35-146. Disponible en: ttp://www.redalyc.org/articulo.oa?id=87619038010. [Consultado el 13 de septiembre de 2017]. El concepto de "bloque de constitucionalidad" se trasladó a España, donde ha tenido un desarrollo jurisprudencial. El Tribunal Constitucional español hizo uso por primera vez de la expresión en el fallo STC 10/82 en el que dicho tribunal se refirió al bloque como "a un conjunto de normas que ni están incluidas en la Constitución ni delimitan competencia, pero cuya infracción determina la inconstitucionalidad 
teórica sino práctica, en la medida en que permite incorporar múltiples estándares normativos del derecho internacional de los derechos humanos al ordenamiento jurídico mexicano, confiriendo al derecho con esta pluralidad normativa un carácter inevitablemente dinámico y creativo. ${ }^{72}$ Por consiguiente, el control de constitucionalidad deberá emplearse no solo frente las disposiciones de la Constitución, sino también a partir de su confrontación con otros dispositivos de carácter supraconstitucional, como los criterios jurisprudenciales, normas, principios y compromisos contenidos en los tratados internacionales, que sin estar formalmente incluidos en la constitución, son utilizados como parámetros de validez de control de constitucionalidad. ${ }^{73}$

La multiplicidad de datos es tal, que México forma parte de 210 tratados internacionales en materia de derechos humanos, ${ }^{74}$ con una pluralidad de derechos, compromisos y obligaciones reconocidos en ellos, así como de la jurisprudencia de vinculación jurídica normativa directa o indirecta en ordenamientos múltiples nacionales e internacionales. Esta multiplicidad de datos que trajo la "tormenta perfecta”, metáfora usada por Flores Saldaña para explicar el paradigma de cambio de nuestro nuevo sistema jurídico caracterizado por una Koiné de los derechos humanos, que, a través del dialogo jurisprudencial, pretende promover un lenguaje común en la interpretación de los derechos humanos contenidos en el bloque de constitucionalidad-convencionalidad; ${ }^{75}$ ha provocado

de la ley sometida a examen”. Vid; (STC 29/1982) (JC, vol. III, pág. 371). Vid; RUBIO LLORENTE, F., "Bloque de constitucionalidad” Revista Española de Derecho Constitucional, año 9, número 27, septiembrediciembre 1989, p. 11. Luego de establecerse en Europa el criterio del "bloque de constitucionalidad" transitó directamente en el constitucionalismo latinoamericano. Así lo encontramos el concepto de "bloque de constitucionalidad” en Colombia vía el artículo 93, Argentina en su artículo 75, Chile en su artículo5 fracción II, Ecuador en su artículo 17, Nicaragua en su artículo 46 y Venezuela en el 23. Con la reforma constitucional en materia de derechos humanos de 2011, México está reconociendo textualmente este concepto, aunque ya lo había hecho por la vía jurisprudencial para referirse al "bloque de constitucionalidad del Distrito Federal en materia electoral”. 9a. Época; Pleno; S.J.F. y su Gaceta; XXV, Mayo de 2007; p. 1641; [J]. Registro No. 172524. Sobre el mismo tema también vid; CARPIO MARCOS, E., "Bloque de constitucionalidad y proceso de inconstitucionalidad de las leyes", Revista Iberoamericana de Derecho Procesal Constitucional, Vol. 4, ed. Porrúa, 2005, pp. 80 y ss.

72 ZAGREBELSKY, G., El derecho dúctil, Madrid, ed. Trotta, 4ª Edición, 2002, p. 112. (Traducción de Marina Gascón).

${ }^{73}$ Vid, ESTRADA VÉLEZ, S., I. Los principios jurídicos y el bloque de constitucionalidad, Colombia, Universidad de Medellín, 2005, p. 79. También vid; Vid; CORZO SOSA, E., "Control constitucional, instrumentos internacionales y bloque de constitucionalidad”, en FERRER MAC-GREGOR, E., y ZALDÍVAR LELO DE LARREA, A., La ciencia del derecho procesal constitucional. Estudios en homenaje a Héctor Fix-Zamudio en sus cincuenta años como investigador del derecho, Tomo IV. Derechos fundamentales y tutela constitucional, México, D.F., IIJ-UNAM, 2008.

${ }^{74}$ Sobre la relación de tratados internacionales de los que el Estado Mexicano es parte en los que se reconocen derechos humanos, vid; http://www2.scjn.gob.mx/red/constitucion/TI.html [Accedido el día 7 de febrero de 2017].

${ }^{75}$ Ante la cultura jurídica, el tratamiento jurisprudencial y el avance dogmático que ha venido concibiéndose bajo el modelo del control de convencionalidad, actualmente exige que en materia de derechos humanos se especifique en definitiva lo que se va a entender por su correlativo bloque de convencionalidad. El cual podemos definir al menos de manera falible y provisional como: "aquel conjunto de disposiciones 
que la multiplicidad de datos sea un rasgo distintivo de los derechos humanos en los sistemas jurídicos posmodernos; ${ }^{76}$ así, la multiplicidad, es sinónimo de la complejidad jurídica plural e interdependiente a los que nos enfrentamos todos los actores jurídicos. ${ }^{77}$

Es evidente que esta multiplicidad del banco de datos sorprende y desconcierta al jurista; -aunque esto es más notorio en el ámbito de los jueces del fuero común-, vemos con acierto como aún los jueces actúan con reserva y con prejuicio a la hora de fundamentar sus resoluciones con estándares convencionales. Solo como precedente, -y no dejando de reconocer un avance-, basta realizar una mirada a la evolución de los criterios contenidos en las tesis jurisprudenciales de la $10^{a}$ época que se han emitido respecto a la aplicación de la cláusula de interpretación conforme, lo concerniente a la jerarquía de los tratados internacionales, el principio pro persona, la vinculatoriedad de la jurisprudencia de la CoIDH, y de los principios constitucionales, para darnos cuenta de la obstinación, la duda y el escepticismo que ha generado y sigue creando este cambio de paradigma constitucional de los derechos humanos. Podemos decir que esta percepción de la multiplicidad en parte, pone en cuestión el sentido de unidad y coherencia en el lenguaje del juez al entablar un dialogo normativo y jurisprudencial. Es decir, ya no se debe interpretar el sistema jurídico desde un criterio unidimensional, cuando la Constitución ya habla de un sistema complejo de relaciones normativas como técnicas de interpretación hacia una multiplicidad de normas, valores y principios constitucionales.

\section{2. Indeterminación y vaguedad de los derechos humanos}

establecidas en la Constitución y en los tratados internacionales que reconocen determinados derechos humanos, a la luz de las cuales se aplica el test del control de regularidad constitucional (constitucionalconvencional) de las leyes y actos de autoridad para su confrontación normativa, con la finalidad de interpretarlas en concordancia con dichas normas, en el sentido que mejor proteja a la persona humana e implique una menor restricción a esos derechos; o en todo caso se encuentre razonable y proporcionalmente justificada” Por consiguiente cuando tratamos bloque de convencionalidad, constituye al mismo tiempo ese mismo bloque de constitucionalidad pero referente a los derechos humanos de fuente nacional e internacional. En este sentido ante esta reformulación del bloque de constitucionalidad-convencionalidad, se presenta el reto significativo para la doctrina jurídica contemporánea, tanto desde la teoría constitucional, como de la teoría de la argumentación e interpretación de constituir una nueva forma de entender el sistema jurídico muy distinto a la metodología jurídica de la modernidad desde la perspectiva meramente legalista. Vid; FLORES SALDAÑA, A., El control de convencionalidad y la hermenéutica constitucional de los derechos humanos, México, D.F., ed. Porrúa, 2014, pp. 88-89 y 147.

${ }^{76}$ El derecho posmoderno es, sin lugar a dudas, un sistema altamente complejo, sea que se considere al sistema jurídico de una nación, de una región o al de derecho internacional. Vid; GRÜN, E., "El derecho posmoderno: un sistema lejos del equilibrio”, Op. Cit., pp. 16-25.

${ }^{77}$ Esta complejidad ocasionada por la multiplicidad de datos, se da también particularmente por un derecho cada vez más abierto e interrelacionado con las tecnologías emergentes como la informática e internet y la biotecnología que se proyectan claramente con el discurso de los derechos humanos, dando lugar a nuevos derechos y a la vez problemas éticos relacionados con el acceso, intercambio y el uso de la información. Vid; DE ASÍS, R., Una mirada a la robótica desde los derechos humanos, Op. Cit., 24-26.Sobre la multiplicidad como característica del derecho posmoderno, vid; GARCÍA INDA, A., "Cinco apuntes sobre Derecho y postmodernidad”, Op. Cit., pp. 11-14. 
Actualmente se reconoce por la comunidad científica que, el derecho en general, y sobre todo el derecho constitucional y los tratados internacionales en donde se reconocen los derechos humanos, contiene un lenguaje conceptualmente vago ${ }^{78}$. Por lo tanto, la vaguedad del derecho es una característica permanente del derecho, de sus recursos lingüísticos y de sus recursos interpretativos. ${ }^{79}$ Es evidente, que ante los nuevos casos que genera la realidad, la ley queda rezagada en el tiempo, desde el momento de su creación legislativa hasta al momento de su aplicación; produciendo una inercia que afecta a las normas jurídicas, las cuales permanecen vigentes cuando han perdido toda su vigencia sociológica, es decir, las normas jurídicas no se ajustan a la realidad que, en el momento de ser promulgadas, les dio justificación. ${ }^{80}$ Como resultado de esto, se genera en el sistema jurídico una tensión entre la realidad y el ideal o valor que plantea la norma abstracta legal. ${ }^{81}$

La indeterminación jurídica también evita problemas si coadyuva a la continuidad y estabilidad de los sistemas jurídicos ${ }^{82}$. Desde esta perspectiva, la indeterminación es más una virtud del derecho que su problema. Por lo que las normas jurídicas que tengan la pretensión de ser duraderas necesariamente tendrán que contemplarse en alguna medida como normas indeterminadas ${ }^{83}$. Por tanto, la indeterminación jurídica, que afecta a los derechos humanos de una constitución concreta, afectará todavía más a los derechos humanos, de vocación internacional. Pues, en opinión del Prof. Peces-Barba, la vaguedad o

\footnotetext{
${ }^{78}$ Vid; ENDICOTT, T., “El derecho es necesariamente vago”, Derechos y Libertades, № 12, 2003, pp.179189.

${ }^{79}$ Vid; ENDICOTT, T., La vaguedad en el derecho, Madrid, Ed. Dykinson, 2007, pp. 237-270. (Trad. J. Alberto del Real y Juan Vega).

${ }^{80}$ Vid; BIDART CAMPOS, G. J., Teoría general de los derechos humanos, Op. Cit., pp. 314-315.

${ }^{81}$ Es Harold Berman quien sostiene que una de las grandes características que presentan los sistemas jurídicos de la modernidad es que siempre hay una tensión: tensión entre la realidad social y el ideal o valor que plantea la norma abstracta legal. Vid; BERMAN, H., Law and Revolution, The Harvard University Press, 1983, pp. 85-119, 273-332

${ }^{82}$ Sobre la persistencia o perdurabilidad como tendencia característica del derecho, vid. HART, H.L.A., El concepto de derecho, Buenos Aires, Ed. Abeledo-Perrot, 1992, pp.26 y ss. (Trad. Genaro R. Carrió).

${ }^{83}$ Sobre la persistencia o perdurabilidad como tendencia característica del derecho, vid. HART, H.L.A., El concepto de derecho, Op. Cit., pp.26 y ss.

${ }^{83}$ Conjuntamente con la indeterminación y vaguedad conceptual, está también el uso limitado con el que utilizamos las palabras, pues como bien afirma Genaro R. Carrió, los términos del lenguaje son susceptibles de abarcar una significación más amplia de la que utiliza cada sujeto en sus contextos particulares. Vid; CARRIÓ, G. R., Notas sobre derecho y lenguaje, Buenos Aires, Ed. Lexis-Nexis, $5^{a}$ Edición, 2006, p.36.La indeterminación del lenguaje común afecta asimismo al lenguaje jurídico, pues no se trata de lenguajes de naturaleza distinta. Vid; sobre el lenguaje común como fundamento del lenguaje legislativo, vid; ITURRALDE SESMA, V., Lenguaje legal y sistema jurídico. Cuestiones relativas a la aplicación de la ley, Madrid, Ed. Tecnos, 1989, pp.31 y ss. Hay que tener en cuenta que el uso limitado y particular de las palabras que utiliza cada sujeto es la causa de la pluralidad de perspectivas, a menudo en controversia, desde la que se interpreta la realidad. De ahí que en el derecho positivo los conceptos ambiguos o vagos sean con frecuencia conceptos controvertidos. Vid; ANSUÁTEGUI ROIG, F.J., "Las definiciones del Estado de derecho y los derechos fundamentales”, Sistema. Revista de Ciencias Sociales, № 158, 2000, pp.93-114. Especialmente el punto primero, 'Conceptos esencialmente controvertidos y tipos de definiciones', pp. 92-98.
} 
generalidad es una nota característica propia del derecho y de los derechos en general. Según sus palabras, referidas en concreto a los derechos humanos: "Los derechos aparecen normalmente enumerados en las constituciones sin que se especifique cuál es su significado concreto. Corresponde a los operadores jurídicos esa asignación. En primer lugar, al legislador, pero a continuación a los restantes sujetos que utilizan el derecho.

Los derechos humanos, al estar situados en los eslabones superiores del ordenamiento, al constituirse en normas básicas materiales, necesitan para su concreción el paso por diferentes operadores jurídicos que poco a poco van delimitando su significado. En este sentido, a la hora de dotar de significado a estos textos normativos con el objetivo de encontrar la norma idónea para justificar la decisión, el papel de la interpretación es clave» ${ }^{84}$; precisamente, desde la teoría del escepticismo realista, consiente de la multiplicidad de datos o normas convencionales, de técnicas interpretativas, y del papel que representan los juristas en la construcción de la dogmática jurídica, toma en serio la equivocidad y la vaguedad del lenguaje de las fuentes del derecho, lo que trae como consecuencia, que, antes de la interpretación, no existe algún sentido objetivo de los textos normativos. ${ }^{85}$ En este sentido para Guastini todo texto normativo es susceptible de interpretaciones diversas, según las cuales, están sincrónicamente controvertidas y que son diacrónicamente variables ${ }^{86}$; de hecho podemos ver como la jurisprudencia de los tribunales en México no es uniforme, sobre todo cuando se trata de casos difíciles o esencialmente controvertidos en materia de derechos humanos, en los cuales es evidente la inexistencia en el juez de criterios o directivas de interpretación que lo lleve a distinguir las respuesta correctas de aquellas incorrectas.

De manera que, la vaguedad e indeterminación de los derechos humanos en el ámbito jurídico-normativo genera un problema a la hora de dar eficacia a tales derechos a través de las decisiones sobre la aplicación e interpretación de las normas jurídicas que los contienen. Como se sabe, las cláusulas generales como la de igualdad y no discriminación, o conceptos jurídicos indeterminados como la dignidad, universalidad, igualdad, libertad, poseen términos o expresiones de textura abierta, con gran plasticidad, que provoca el inicio de la significación que deberá ser complementada por el intérprete, tomando en consideración las circunstancias del caso en concreto. ${ }^{87}$ Que todos estos problemas se incrementen para los derechos humanos, parece estar en la base de su menor eficacia y de su mayor ambigüedad interpretativa, dado que su ubicación en el ámbito internacional hace que todo sea mucho más complejo para los derechos. ${ }^{88}$ Por esa causa, entre otras a

\footnotetext{
${ }^{84}$ PECES-BARBA, G., Curso de derechos fundamentales. Teoría general (con la colaboración de R. de Asís Roig, C. R. Fernández Liesa y A. Llamas Gascón), Madrid, Universidad Carlos III-B.O.E., 1999, pp.578-579.

${ }^{85}$ Vid; GUASTINI R., Nuevos estudios sobre la interpretación, Colombia, Universidad de Externado de Colombia, 2010, pp. 98-99. (Traducción de Diego Moreno Cruz).

${ }^{86}$ Vid; GUASTINI, R., Nuevos estudios sobre la interpretación, Op. Cit., p. 100.

${ }^{87}$ Vid; BARROSO, L. R., El neoconstitucionalismo y la constitucionalización del derecho, México, D.F., IIJUNAM, 2008, p. 13.

${ }^{88}$ Vid; ANGULO LÓPEZ, G., Teoría Contemporánea de los derechos humanos, Op. Cit., p. 61.
} 
considerar, dicha relación es especialmente verificable en las normas constitucionales y en los conceptos y términos jurídicos relacionados con los derechos que las mismas acogen, y en la realidad temporal también extensible a los contenidos normativos reconocidos en los tratados internacionales.

\section{III.3. La ductilidad en la hermenéutica principialista y iusfilosófica}

En efecto, actualmente, el derecho se concibe como un sistema complejo, práctico y flexible, ya Zagrebelsky afirmaba que la mejor característica que describe hoy al derecho es su “ductilidad”. El derecho es dúctil, y la ductilidad en el derecho es sobre todo ductilidad constitucional. El autor italiano entiende la ductilidad como la catalogación que permite expresar el carácter esencial del derecho en los Estados constitucionales actuales; precisamente la ductilidad de la Constitución es, por una parte, lo que facilita a esta mantener sus fines de unidad e integridad al posibilitar la coexistencia de valores y principios diferentes en un mismo sistema jurídico; así, la doctrina del diritto mitte, considera al derecho no como un "dato", sino como un incesante "hacerse" donde convergen innumerables exigencias planteadas por varios principios a veces contradictorios que pretenden venir realizados en el contacto con la realidad viva de las experiencias sociales ${ }^{89}$; así, la ductilidad es quizás una de las características más sobresaliente del paradigma constitucional como una red normativa, concebida como una estructura abierta y flexible, capaz de expandirse sin límites; como hemos referido, además de la multiplicidad jurídica se produce su estiramiento convirtiendo al derecho en un discurso dúctil, blando, flexible,-por utilizar la acertada expresión de Jean Carbonnier-; ${ }^{90}$ por lo tanto, adaptarnos a este rasgo propio de la posmodernidad jurídica ${ }^{91}$ puede llegar a tener en los jueces un efecto de desconcierto inicial que puede llegar a convertirse en escepticismo. Sin embargo, el reto consiste justamente en lo contrario, en abordar esta realidad jurídica múltiple y flexible sin caer en el prejuicio y la desconfianza, logrando así, que estos criterios tengan un efecto útil, inmediato y pragmático en los jueces en la resolución de casos difíciles y controvertidos desde una perspectiva de derechos humanos. ${ }^{92}$

Justamente con el motivo del ingreso a la Constitución mexicana de principios y valores constitucionales con la reforma constitucional ha dado lugar a una Constitución axiológicamente generosa que repercute por consiguiente en la moralización del

\footnotetext{
89 Vid; ZAGREBELSKY, G., El derecho dúctil, Op. Cit., pp. 122-124. DEL REAL ALCALÁ, A., "Cuestionamiento del ideal de certeza en el derecho: Hart-Zagrebelsky-Endicott”, México D.F., IIJ-UNAM, Boletín Mexicano de Derecho Comparado, núm. 131, 2011, pp. 690-691.

${ }^{90}$ Vid; CARBONNIER, J., Derecho flexible. Para una sociología no rigurosa del derecho, Madrid, Tecnos, 1974. (Traducción y prólogo de L. Díez-Picazo).

${ }^{91}$ Sobre las implicaciones del derecho posmoderno, vid; ARNAUD, A. J., "Los juristas frente a la sociedad (1975-1993)”, Op. Cit., También vid; GARCÍA INDA, A., "Cinco apuntes sobre derecho y posmodernidad”, OP. Cit., pp. 1-39 y GRÜN, E., "El derecho posmoderno: un sistema lejos del equilibrio”, Op. Cit., pp. 16-25.

${ }^{92}$ Vid; ANGULO LÓPEZ, G., "La ductilidad como núcleo esencial del derecho: la reforma al artículo $1^{\circ}$ de la Constitución Mexicana”, Revista de Estudios Jurídicos nº 14/2014, España, (Segunda Época), pp. 1-5.
} 
razonamiento jurídico; ${ }^{93}$ es claro que la concepción del derecho reducido solo a un conjunto de normas y reglas (normativismo rígido), ha quedado ya superado. Principios como el pro persona, el de universalidad, interdependencia, indivisibilidad y progresividad tienen un peso normativo capaz de regular la validez de cualquier resolución jurídica o disposición legal, reglamentaria o acto de autoridad pública o privada, creando verdaderamente un cambio sustancial respecto a la noción que sobre el derecho se tenía antes de la reforma constitucional en materia de derechos humanos en México.

Precisamente a este conjunto de principios, valores, derechos y directrices se les denomina como las nuevas piezas fundamentales del derecho moderno, que tiene como una de sus características principales servir como criterios de interpretación del derecho subconstitucional, ${ }^{94}$ el cual exige un cambio en la dinámica interpretativa de los jueces orientados a reforzar el contenido material de la Constitución, y por ende la aplicación de la argumentación y de modernos métodos hermenéuticos dentro de los procesos judiciales. Asimismo, esto lleva a los jueces a no solo a analizar, interpretar y aplicar el derecho, sino a identificar el derecho válido sobre la realidad actual, y el modo en que deberán operar en él y con él, caracterizado por lo existencia de un derecho por principios que los vincula a ajustarse a la instrumentación de métodos distintos como los de ponderación, corrección funcional, razonabilidad o proporcionalidad, junto con las herramientas hermenéuticas como el principio de proporcionalidad, el contenido esencial de los derechos humanos, la cláusula de interpretación conforme, el principio pro persona, etc., con lo que se renueva su propia actividad judicial. Justamente, la principialización del derecho ha llevado a que los tribunales en México empiecen a comprender la importancia de la interpretación en base a los valores y principios constitucionales como las normas más relevantes del paradigma constitucional de los derechos humanos.

En efecto, el papel que en los últimos años ha asumido el operador jurídico en México al desprenderse de los métodos de interpretación tradicionales e involucrarse en las nuevas dinámicas de la interpretación y argumentación jurídica, ha favorecido la justificación de decisiones racionales y razonables conforme a los derechos humanos reconocidos en los tratados internacionales y en la jurisprudencia de la Corte IDH, lo cual revela ya la importancia que el juzgador asume en la aplicación de nuevos estándares a través de la labor argumentativa y hermenéutica judicial. Precisamente, Konrad Hesse señala que los métodos de interpretación constitucional no se deben limitar a aquellos

\footnotetext{
${ }^{93}$ Vid; GARCÍA FIGUEROA, A., Criaturas de la moralidad, una aproximación neoconstitucionalista al derecho a través de los derechos, Madrid, Trotta, 2009, p. 65.

${ }^{94}$ Atienza y Ruiz Manero describen algunas de las características que se le han atribuido a este este conjunto de principios, valores, derechos y directrices, que han denominado como las nuevas piezas fundamentales del derecho, al señalar que son: a) normas muy generales; b) redactadas en términos particularmente vagos; c) programáticas en el sentido de que imponen la obligación de perseguir determinados fines; d) expresan los valores superiores del ordenamiento jurídico y; d) sirven como criterios de interpretación del derecho subconstitucional, por mencionar solo algunos. Vid; ATIENZA M., /RUIZ MANERO, J., Las piezas del derecho, Barcelona, Ariel, 1996, p. 4.
} 
criterios clásicos de interpretación normativa como (el literal, teleológico, sistemático e histórico), que postulaba Savigny en el siglo pasado para interpretar las leyes, y que fueron defendidos con valor frente a nuevos métodos aparentemente extraños a la ciencia del derecho; ${ }^{95}$ pues resultaban acotados dentro de un sistema jurídico con nuevos paradigmas de interpretación, en los cuales se deben de incorporar una serie de principios, criterios, métodos y razonamientos novedosos al ejercicio hermenéutico de los jueces, sobre todo para la solución de casos difíciles o esencialmente controvertidos en materia de derechos humanos, maximizando la posibilidad de tener efectos prácticos sobre la realidad social; ${ }^{96}$ es decir, el intérprete debe buscar la interpretación que más optimice el contenido y el alcance de un derecho humano; pues cada disposición constitucional, como sostiene Häberle, "está dirigida a la realidad” y, en ese sentido, esta requiere de una interpretación orientada a la efectividad de la vigencia práctica material. ${ }^{97}$

En este sentido, Alexy sostiene que en el caso de los principios como requisitos de optimización, son normas que requieren que algo se realice con la mayor amplitud posible dentro de las posibilidades jurídicas y fácticas”. 98 Por lo tanto, será necesario que quien pretenda llegar a una norma de decisión, debe pretender, además, que su decisión sea moralmente correcta, que sus criterios o resoluciones no vayan en contra de la coherencia de dichos principios; por eso, cuando Alexy sostiene que los principios son mandatos de optimización, exige a los jueces que no solo se conformen con una única respuesta jurídica dada, sino que se inmersen en la búsqueda del contenido moral y forma jurídica más favorable para resolver el caso de que se trate. ${ }^{99}$ Así, lo que exige la norma [N] no es, o no es solo, la producción de algo, sino la selección de los medios óptimos para conseguir o maximizar algo dada las circunstancias del caso.

Los principios como mandatos de optimización, nos ayudan a determinar los casos controvertidos, por ejemplo (determinar lo que es "familia”, a distinguir las "posiciones preferentes" de los sujetos en el caso de proteger el derecho a la propia imagen y a la intimidad/privacidad; o para determinar si la finalidad del matrimonio es la "procreación”,

\footnotetext{
${ }^{95}$ Vid; SÁNCHEZ GIL, R., "Hacia un nuevo modelo de interpretación constitucional”, Revista de la Facultad de Derecho de México, México, UNAM, Facultad de Derecho, t. LVIII, núm. 249, enero-junio de 2008, p. 320. Versión electrónica en http://bit.ly/1fRLala.

96 Sobre los modelos de interpretación neoconstitucionales, vid; HESSE, K., Escritos de derecho constitucional, Madrid, 2da. Ed. Centro de Estudios Constitucionales, 1992, pp. 45-47. (Traducción de Pedro Cruz Villalón).

${ }_{97}$ Vid; HÄBERLE, P., La libertad fundamental en el Estado Constitucional, Lima, Fondo Editorial de la PUCP, 1997, p. 328 y 263

${ }^{98}$ Vid; ALEXY, R., “Ponderación, control de constitucionalidad y presentación”, trad. De la Vega, René, G., en, CARBONELL, M., /VÁZQUEZ, R., y OROZCO HENRÍQUEZ, J., (Coord.), Jueces y ponderación argumentativa, México, D.F., IIJ-UNAM, 2006, p. 2.

99 ALEXY, R., El concepto y la validez del derecho, Barcelona, Gedisa, 1997, (trad. de Jorge M. Seña), pp. 63-64.
} 
o si es inherente al diseño racional de la figura del matrimonio; ${ }^{100}$ también, va a ayudar al juez a justificar los “juicios de relevancia”"101 ante un trato jurídico diferenciado hacia dos personas y no entrar en conflicto con el principio de igualdad y no discriminación; para fijar los límites a una “autonomía” que quiere manifestarse en el caso de la legalización del consumo de la marihuana para efectos lúdicos o recreativos; ${ }^{102}$ o, a la noción de ser humano o de "agente moral" en el caso de establecer el alcance de la dignidad humana ante el desarrollo de las tecnologías emergentes dirigidas a mejorar la vida de los seres humanos, como: la informática e internet, biomedicina, neurociencias, nanociencia y nanotecnología y la robótica; ${ }^{103}$ para poder así, tener una aproximación racional ${ }^{104}$ que nos de las razones que justifiquen el paso de los enunciados interpretativos a una norma de decisión. ${ }^{105}$

Desde esta perspectiva, la hermenéutica que exige el nuevo paradigma constitucional, ya no se plantea solo la existencia de un método de interpretación científico, lógico o de laboratorio a través del cual se llegan a la respuestas de forma mecánica, deductiva o causalista; sino que lleva además a la necesidad de que el juez se replantee el fenómeno mismo de la comprensión desde una hermenéutica iusfilosófica ${ }^{106}$ y no se limite únicamente al uso del método, sino que descubra en el acto mismo del conocer humano, la experiencia de verdad, de una realidad, de un contexto que lo aproxime a interpretar la conducta humana de una forma más abierta, lejos del aspecto lineal, monológico y cerrado, que impide que los jueces puedan realizar una traducción del mejor contenido axiológico, social, real, moral, normativo de los derechos humanos al contenido argumentativo de las decisiones judiciales. En este sentido, para Atienza el derecho no puede concebirse solamente como una realidad ya dada, como el producto de una actividad

\footnotetext{
${ }^{100}$ Sobre la finalidad del matrimonio véase la Jurisprudencia de la SCJN, Tesis: $1^{\mathrm{a}} / \mathrm{J} .43 / 2015$, Primera Sala, Décima Época, publicada el viernes 19 de junio de 2015 en la Gaceta del Semanario Judicial de la Federación; https://www.scjn.gob.mx/libreria/Paginas/semanarioauto.aspx [Accedido el día 26 de abril de 2016].

101 Sobre los juicios de relevancia conviene ver la obra de LAPORTA F. J., «Principio de igualdad: introducción a su análisis», Sistema. Revista de Ciencias Sociales, No 67, 1985, pp. 20-24.

${ }^{102}$ Sobre la regulación del consumo de la marihuana para "efectos lúdicos o recreativos", véase la resolución de la Primera Sala de la SCJN del Amparo en Revisión 237/2014.

${ }^{103}$ Sobre las problemáticas y exigencias que plantea el derecho actual en el contexto de las tecnologías emergentes vid; DE ASÍS, R., Una mirada a la robótica desde los derechos humanos, Op. Cit., pp. 23.34.

${ }^{104}$ Sobre la aplicación de los principios como mandatos de optimización vid: ANGULO LÓPEZ, G., "The interpretation of human rights according to international treaties: notes for their jurisdictional application in Mexico”, The Age of Human Rights Journal, nº 6 junio 2016, pp. 9-12.

${ }^{105}$ Una de las cuestiones relevantes que es necesario señalar, es la importancia del estudio de la teoría de la argumentación jurídica, tanto para la solución de cuestiones esencialmente controvertidas relativas a la interpretación jurídica, como para la construcción de buenos argumentos que justifiquen y le den validez a la norma de decisión. Vid; ATIENZA, M., Las razones del derecho. Teoría de la argumentación jurídica, México, IIJ-UNAM, 2007, p. 2.

106 Sobre las implicaciones de la hermenéutica iusfilosófica en las decisiones judiciales, Vid; FLORES SALDAÑA, A., El control de convencionalidad y la hermenéutica constitucional de los derechos humanos. Op. Cit., p. 158.
} 
o de una voluntad, sino, además y primordialmente como una práctica social que incluye una pretensión de corrección o de justificación. De esta forma los derechos humanos se asumen no como simples convenciones, sino como derechos que tienen su fundamento en una moral universal justificada racionalmente. En este contexto, la interpretación jurídica toma especial relevancia como una actividad orientada por la necesidad de cumplir con el objeto, fin, principios y valores que dan sentido a la práctica judicial, integrando en un todo armónico la dimensión autoritativa del derecho con el orden de valores expresados en los principios constitucionales. $^{107}$

\section{III.4. EL PARADIGMA DE LA CONSTITUCIONALIDAD COMO UNA “RED NORMATIVA”}

El derecho posmoderno y las implicaciones que tienen sus características en el nuevo paradigma constitucional de los derechos humanos en México, convergen con otras tensiones que ponen en riesgo la coherencia, validez e integridad del sistema jurídico. Como por ejemplo, el caso de las restricciones expresas impuestas al ejercicio de los derechos humanos, criterio jurisprudencial derivado de la contradicción de tesis 293/2011 de la SCJN, que trajo como consecuencia, una tensión entre los derechos humanos de fuente internacional y las de fuente constitucional, al establecer que:

“[...]las normas de derechos humanos, independientemente de su fuente, no se relacionan en términos jerárquicos, entendiendo que, derivado de la parte final del primer párrafo del citado artículo 1o., cuando en la Constitución haya una restricción expresa al ejercicio de los derechos humanos, se deberá estar a lo que indica la norma constitucional; [...] lo que sí ha evolucionado a raíz de las reformas constitucionales en comento es la configuración del conjunto de normas jurídicas respecto de las cuales puede predicarse dicha supremacía en el orden jurídico mexicano. Esta transformación se explica por la ampliación del catálogo de derechos humanos previsto dentro de la Constitución Política de los Estados Unidos Mexicanos, el cual evidentemente puede calificarse como parte del conjunto normativo que goza de esta supremacía constitucional. En este sentido, los derechos humanos, en su conjunto, constituyen el parámetro de control de regularidad constitucional, conforme al cual debe analizarse la validez de las normas y actos que forman parte del orden jurídico mexicano." 108 (Subrayado y negrita añadido).

En este razonamiento de la SCJN se producen varios temas que merecen mayor reflexión, como: a) la jerarquía de los tratados internacionales en materia de derechos humanos en relación con la Constitución; y b) la vinculatoriedad de la jurisprudencia de la CoIDH, sin embargo, por no ser objeto del presente estudio, nos aproximaremos a analizar particularmente los efectos de las restricciones al ejercicio de los derechos humanos que tienen sobre el paradigma constitucional.

107 Vid; ATIENZA, M., Curso de argumentación jurídica, 1ª edición, Madrid, Trotta, 2016, p. 29. (El ejemplar citado corresponde a la $4^{\mathrm{a}}$ reimpresión de la $1^{\mathrm{a}}$ edición de 2013.

${ }^{108}$ PLENO. Contradicción de tesis 293/2011. 
Ahora bien, esta jurisprudencia de la SCJN a 4 años de su publicación, aún no se vislumbra hasta el momento una señal de reajuste del criterio, dejando posturas ambivalentes en esta compleja relación de balance entre la vigencia práctica real de las restricciones constitucionales, y la validez de los principios y contenidos normativos del derecho internacional de los derechos humanos. Es por ello, que esta postura de la SCJN contiene un alto grado de contemporaneidad, ${ }^{109}$ ya que este razonamiento se hace vigente con la circunstancia del pasado, con las posibilidades de sentido, significado y alcance que implican a nuestra realidad jurídica actual. Por lo tanto, consideramos que este criterio de la SCJN ha sido la sentencia más importante y significativa del neoconstitucionalismo mexicano por dos motivos.

En primer término, es indiscutible que en base a este criterio de la SCJN, si los derechos humanos reconocidos en los tratados internacionales y los criterios jurisprudenciales de la CoIDH pierden fuerza normativa, validez y eficacia por ir en sentido contrario a alguna restricción constitucional, trae como consecuencia una retracción al proceso de armonización entre el derecho nacional y el derecho internacional; pues al tener a la Constitución como única fuente normativa para restringir o intervenir legítimamente los derechos humanos, se separa del parámetro de validez y de protección de los derechos humanos en función del principio pro persona; en segundo lugar, rompe con el círculo hermenéutico; es decir, no se puede quedar dividido en el binomio excluyente, interpretación-aplicación; no se puede separar la aplicación de una norma de su interpretación en tanto que forma un proceso unitario de comprensión.

Está claro que ante este escenario de conflicto de normas, aparece la necesidad de restringir o limitar un principio o un derecho humano; sin embargo, hay que considerar que ante todas las posibilidades de restricción o limitación de derechos y principios, conllevan a su vez su propio límite, que reside principalmente en el respeto al contenido esencial de los mismos en función de sus límites estructurales. Por consiguiente, consideramos que el método de jerarquización de normas que aplicaron los ministros de la SCJN para resolver la “colisión de derechos”, dejaron de lado los procesos de balance, de ponderación, de armonización, así como la doctrina jurídica internacional, y su tratamiento científico contenido en las sentencias de los tribunales supranacionales que hubiesen ayudado a mantener el equilibrio y la coherencia del sistema jurídico

Justamente, Flores Saldaña considera que con este criterio restrictivo de la SCJN surge lo que denomina el impasse normativo, el cual consiste en la paradoja de contar con un "parámetro de regularidad constitucional” incompleto, pues no solo es la Constitución la norma sobre la cual se van a juzgar e interpretar los actos y leyes del poder público en

${ }^{109}$ La contemporaneidad para Hans Gadamer, es: “que algo único que se nos representa por lejano que sea su origen, gana en su representación una plena presencia. La contemporaneidad no es, pues, el modo como algo está dado a la conciencia, sino que es una tarea para ésta y un rendimiento que se le exige.” ${ }^{109}$ GADAMER, H. G., Verdad y método, fundamentos de una hermenéutica filosófica II, $2^{\mathrm{a}}$ ed., ediciones Sígueme, Salamanca, 1994, p. 140. 
cuanto a las restricciones justificadas a los derechos humanos. Para Flores Saldaña, "las restricciones constitucionales a los derechos humanos, desde el parámetro constitucional constituye un auténtico callejón sin salida, [...] el círculo hermenéutico se rompe y la dialéctica entre normas de derechos humanos encuentra una pared infranqueable desde los parámetros estrictamente constitucionales, sin acudir a todo el bloque de constitucionalidad al que está obligado el operador jurídico nacional”. ${ }^{110}$ Ciertamente, como sostiene Ramelli, el "bloque de constitucionalidad" surge por "la necesidad de armonizar el contenido del principio de supremacía constitucional con el de primacía de derecho internacional”. ${ }^{111}$

En esta misma línea argumentativa, el ministro de la SCJN José Ramón Cossío considera que debería darse la plena igualdad entre los derechos humanos, tanto los de fuente constitucional como los de fuente convencional; pero, que al introducirse una diferenciación entre uno y otro tipo de derechos al darle preeminencia jerárquica a las restricciones constitucionales, tal igualdad normativa se rompió. ${ }^{112}$ Por consiguiente, sostenemos que, con este criterio de la SCJN se fractura el "bloque de constitucionalidad", lo cual implica, que ese conjunto de normas de derechos humanos que configuraban una unidad constitucional representada en un bloque, y,- considerado por la propia SCJN-, como el parámetro de validez constitucional de las restantes normas del ordenamiento jurídico mexicano, se fragmente, creando en el vacío que los separa la vía de una tercera figura, que, por su complejidad, podría responder a la juridicidad constitucional en forma de "red"; pues al haberse fracturado el "bloque de constitucionalidad", -no se fragmenta para luego restaurarse el bloque, ni para erigirse de nuevo la pirámide de Kelsen-, sino que surge de manera espontánea una figura en forma de "red”, que por su misma estructura compleja y laberíntica, podría responder a la dispersión de la multiplicidad de datos convencionales, precedentes, teorías, principios, valores y discursos que operan como parámetros de validez y como cánones hermenéuticos que informan de todo el sistema jurídico.

De hecho, Alejandro Pérez Hualde, al analizar el sistema constitucional en Argentina, nos aporta elementos que refuerzan el paradigma de la constitucionalidad como una red

110 FLORES SALDAÑA, A., El control de convencionalidad y la hermenéutica constitucional de los derechos humanos, Op. Cit., p 138.

111 RAMELLI ARTEAGA, A., "Sistema de Fuentes del Derecho Internacional Público Bloque de Constitucionalidad”, en, Eduardo MONTEALEGRE LYNETT, Eduardo, (Coord.), Anuario de Derecho Constitucional, Análisis de la Jurisprudencia de la Corte Constitucional de Colombia, Bogotá, Universidad Externado de Colombia, $1^{\text {a }}$ ed. 2003, p. 234.

${ }^{112}$ El ministro Cossío sostuvo que la posición mayoritaria de los ministros de la SCJN en la resolución de la contradicción de tesis 293/2011, terminó generando una regla universal de interpretación, por virtud de la cual, el derecho convencional cede frente al derecho constitucional desplazando la posibilidad de resolver los problemas caso por caso aplicando efectivamente el principio pro persona. El ministro afirma, que es una falacia considerar que la interpretación generada por ella permita la ponderación caso por caso de todos los derechos humanos. Para que ello fuera así, Cossío considera que debería darse la plena igualdad entre los derechos humanos, tanto los de fuente constitucional como los de fuente convencional. Vid; COSSÍO DÍAZ, J. R., "Las trampas del consenso", Revista Nexos, octubre 2013. http://www.nexos.com.mx/?p=15502. [Accedido el día 5 de febrero de 2017]. 
normativa al señalar que, después de la década de 90’s. Argentina ingresó fuertemente en el neoconstitucionalismo moderno, generando una verdadera revolución en la teoría jurídica tradicional, respecto a lo que se conoce como la pirámide jurídica de Hans Kelsen, la concepción de la existencia de una norma fundamental (el vértice de la pirámide) y la posibilidad posterior de, mediante la pura lógica formal, deducir toda la normativa del Estado, ha sido desplazada por una red de normas. "El ordenamiento piramidal que sirvió de imagen básica a la estructura del derecho tiende a cobrar el aspecto de una red compleja de instituciones y actores sociales en conflicto, con una lógica propia difícilmente reductible a la dinámica y la estática de la teoría tradicional del Derecho y del Estado". ${ }^{113}$ Para este autor, en el derecho público argentino hay toda una trama de derechos humanos fundamentales, sobre todo de derechos de corte social, que no vinieron solos, están acompañados de procedimientos, tribunales y fuentes jurídicas de orden internacional. En este sentido, sostiene este jurista que, en la actualidad, es evidente, que la Constitución argentina ya no tiene más 129 artículos porque hay que considerar todos los tratados internacionales incorporados que están en la misma jerarquía. Por lo tanto, considera que los jueces deben trabajar no con una pirámide normativa, sino con una red de normas, donde son muchas las fundamentales. Así, señala que los derechos humanos tienen sus propias reglas de interpretación, como los principios pro persona y pro debilis. "Esta novedad con la que debemos trabajar jueces, administradores y legisladores, implica una auténtica transformación del derecho”.114

En definitiva, cabe aclarar que en base a este criterio de la SCJN, al activarse los contenidos normativos de derechos humanos de fuente internacional, solo se relacionarán en términos de jerarquía cuando se encuentren con las restricciones constitucionales, las cuales, cabe la posibilidad de que puedan ponderarse, y, por lo demás, interactuarán en términos de armonización, de coordinación, en una especie de red, en el que el derecho es uno, construido por diferentes fragmentos normativos interpretados de forma armónica e integradora tanto con la Constitución como con los tratados internacionales en donde se encuentren regulados los derechos humanos; de tal manera que, Constitución e interpretación se fusionan de forma tangible; así, la red de validez normativa estará integrada por una multiplicidad de normas formalmente constitucionales, por normas creadas jurisprudencialmente, principios, valores, directrices, contenidos normativos de los

\footnotetext{
113 Vid, ZULETA PUCEIRO, E., Teoría del Derecho. Enfoques y aproximaciones, Buenos Aires, Lexis Nexis, 2005, p. XIV, citado por PÉREZ HUALDE, A., "Reflexiones sobre el neoconstitucionalismo y derecho administrativo, en, Anuario da Facultade de Dereito da Universidade da Coruña, 2008, p. 762. Versión electrónica: http://ruc.udc.es/dspace/bitstream/handle/2183/7459/AD_12_art_40.pdf?sequence=1 Del mismo autor, vid; "Reflexiones sobre el neoconstitucionalismo y derecho administrativo", en, BÉJAR RIVERA, L. J., (Coord.), Derecho Administrativo. Perspectivas Contemporáneas, México, D.F., ed. Porrúa, 2010, pp. 1-34.

114 PÉREZ HUALDE, A., "No hay una pirámide sino una red jurídica", La Gaceta, 3 de julio de 2007, http://www.lagaceta.com.ar/nota/224740/tribunales/no-hay-piramide-sino-red-juridica.htm. [Accedido el día 22 de julio de 2017].
} 
tratados internacionales que determinarán a su vez los criterios de validez del resto de las normas del sistema jurídico. ${ }^{115}$

\section{CONCLUSIONES}

En conclusión, ante las actuales tensiones y complejidades que presenta la realidad jurídica mexicana, la única posibilidad de encontrar una salida se encuentra en la ruta de una nueva toma de conciencia ampliada a las dimensiones del bienestar de los intereses colectivos; es decir, tiene que pasar por un profundo cambio de mentalidad de la sociedad en su conjunto, que la lleve a replantearse su relación con los demás y con su entorno. Es evidente que en México, la política se está quedando muy atrás respecto de las necesidades humanas, ya que se percibe un permanente discurso que nos indica una visión cada vez más desajustada de la realidad social; pareciera que nuestro sistema jurídico-político actual está justamente como señala Piscitelli, -en estado lejos del equilibrio-, entre un gobierno controlado y un gobierno efectivo; entre una norma reconocedora de derechos y su real eficacia jurídica en las relaciones humanas. ${ }^{116}$ El posmodernismo resulta de este modo más bien un tipo de sensibilidad ante el grupo, que un fundamento racional irrefutable; en tal sentido, la posmodernidad jurídica se trata de cierta sensibilidad individual crítica, ante los fundamentos del pensamiento jurídico y social moderno.

Desde esta reformulación, se presenta un gran reto para el sistema jurídico mexicano contemporáneo, el de afrontar sus deficiencias y solucionar determinados problemas relacionados con la eficacia, con la praxis y el bienestar social; e incorporar al paradigma original los nuevos sujetos, actores, destinatarios, reivindicaciones que surgen ante los diferentes problemas que afectan al ser humano, para propiciar, con esto, una expectativa más amplia de reflexión acerca de lo que es ser persona, para repensar el derecho, la práctica que lo efectiviza, la ciencia que lo estudia, no como fenómeno inmutable, sino en constante transformación, como un sistema en forma de red, compuesto de elementos complejos, múltiples, flexibles, en interacción dinámica con factores de la vida jurídica y la realidad social. Esto constituye para nosotros, la apuesta más considerable del derecho posmoderno. $^{117}$

En relación al funcionalismo penal radical, nos parece exagerada la visión de Jakobs al considerar la estabilización del orden social como la única y principal función del derecho penal. Jakobs, pretende defender la idea del consenso con el derecho penal como único medio para proteger los intereses sociales $y$ entra en conflicto con las

\footnotetext{
115 Sobre los efectos de la resolución de la contradicción de tesis 293/2011 de la SCJN en el bloque de constitucionalidad, véase las opiniones del Ministro Arturo Zaldívar Lelo de la Larrea en: https://www.youtube.com/watch?v=S6lYgPUMw1A [Accedido el 21 de agosto de 2017].

${ }^{116}$ Vid; PISCITELLI, A., Ciberculturas en la era de las máquinas inteligentes, Buenos Aires, Paidós, 1995.

${ }^{117}$ Sobre los rasgos de la posmodernidad jurídica, vid; DE TRAZEGNIES GRANDA, F., Postmodernidad y Derecho, Bogotá, Colombia, ed. Temis, 1993.
} 
transformaciones de la realidad social y los sistemas jurídicos altamente complejos, pues, al no precisar objetivamente las características del sistema social sobre el cual funcionaría su teoría, sus ideas se diluyen en un sistema social abstracto, resultando incompatibles con las distintas formas de organización social y de sistemas de justicia que legitiman el orden político-criminal. No obstante, coincidimos con Jakobs en su perspectiva sociológica del derecho penal, es claro que no podemos concebir un sistema de justicia penal como un conjunto de normas carentes de sentido social en su función de estabilizar o mantener el orden.

En esta misma línea argumentativa, Jakobs nos dice que la persona existe en función de su relación con los demás, la cual se define a través del cumplimiento de normas válidas dirigidas a proteger las expectativas o intereses del grupo social. Es claro, que en el momento en que nos damos cuenta lo que queremos para nosotros, por ejemplo, un comportamiento que respete nuestra integridad personal, es válido también para los demás; y a pesar de que con esa idea nace un sentido de justicia que puede ser expresado más claramente con las palabras de Ricoeur, tomadas de su obra Sí mismo como otro" regla de no hacer a los demás lo que no queremos que nos hagan a nosotros"; ${ }^{119}$ no estamos de acuerdo bajo ningún contexto, que una persona que viole esa regla, y en consecuencia defraude con ese comportamiento las expectativas del grupo social, sea tratada como producto de una construcción normativa, y no como si fuera una persona, es decir, que con su conducta provoque que la categoría de "derecho humano" referida al estatus de "persona” resulte inadecuada; una cosa son las medidas restrictivas que se aplicarían al imputado como mecanismos de seguridad y de investigación criminal y otra despojarlo de su posición de persona promoviendo penas extremadamente injustas como la muerte u otras medidas contrarias e incompatibles con el mínimum core content de los derechos humanos. $^{120}$

En definitiva, ante las tensiones actuales que presenta el sistema penal y de seguridad en México, creemos que el reto más importante de la reforma de justicia penal, no está en la implementación del sistema acusatorio y garantista, sino en lograr su legitimación social a través de la credibilidad y confianza de los ciudadanos en sus operadores; y esto solo podrá darse en tanto los operadores políticos y jurídicos conciban que el modelo de un sistema penal acusatorio solo será aceptado como una concepción genuinamente igualitaria y garantista, en tanto se reconozca que el discurso sobre los derechos humanos encubre una gran desigualdad estructural en el sistema de justicia penal. De esta manera, se irá disminuyendo la tensión que según Harold Berman está presente no solo en el sistema de justicia penal mexicano, sino en todos los sistemas jurídicos modernos occidentales, esa

\footnotetext{
${ }^{118}$ Vid; RICOEUR, P., Sí mismo como otro, Madrid, Siglo XXI, 1998.

119119 Desde nuestro punto de vista esta sería la fórmula original para dar solución a algunos conflictos de intereses o valores relacionados con la justicia.

120 Alexy sostiene las normas jurídicas, debidamente promulgadas y socialmente eficaces, que son incompatibles con el núcleo de los derechos humanos básicos, son extremadamente injustas y, por tanto, no son derecho. Vid; ALEXY, R., La institucionalización de la justicia, Granada, Ed. Comares, 2010, p.66.
} 
tensión que la justicia en términos dialecticos ha generado: tensión entre la realidad social bienestar de la comunidad-, y los derechos humanos de la persona, -el valor que plantea la norma abstracta legal-. ${ }^{121}$ En definitiva, más allá de la posibilidad de adoptar un funcionalismo penal riguroso para restablecer los niveles razonables de seguridad y de eficacia de los derechos humanos en México, si no se disponen de instituciones sólidas y democráticas, de una litigiosidad social mínima y de estrategias y políticas orientadas a la culturalización del sistema penal acusatorio, a la prevención del delito, a eficientizar la investigación científica criminal de los delitos y de combate a la corrupción e impunidad, poco o nada se podrá hacer aun teniendo las mejores reformas de justicia penal, de seguridad y de protección de los derechos humanos en México.

\section{BIBLIOGRAFÍA}

AARNIO Aulis, /ATIENZA, Manuel, /LAPORTA Francisco, J., Bases teóricas de la interpretación jurídica, Madrid-México, Fontamara, $1^{\text {a }}$ ed. 2013.

ALEXY, Robert, La institucionalización de la justicia, Granada, ed. Comares, 2010.

ALEXY, R., "Ponderación, control de constitucionalidad y presentación”, trad. De la Vega, René, G., en, CARBONELL, M., /VÁZQUEZ, R., y OROZCO HENRÍQUEZ, J., (Coord.), Jueces y ponderación argumentativa, México, D.F., IIJ-UNAM, 2006.

Tres escritos sobre los derechos fundamentales y la teoría de los principios, Colombia, Universidad Externado de Colombia, Serie de Teoría Jurídica y Filosofía del Derechos, $\mathrm{N}^{\circ}$ 28, 2003. (Trad. Carlos Bernal Pulido).

El concepto y la validez del derecho, Barcelona, Gedisa, 1997, (trad. de Jorge M. Seña).

ANGULO LÓPEZ, Geofredo, "The interpretation of human rights according to international treaties: notes for their jurisdictional application in Mexico", The Age of Human Rights Journal, $\mathrm{n}^{\circ}$ 6, 2016.

Teoría contemporánea de los derechos humanos, Madrid, Dykinson, 2015.

"La ductilidad como núcleo esencial del derecho: la reforma al artículo $1^{\circ}$ de la Constitución Mexicana”, Revista de Estudios Jurídicos n ${ }^{0}$ 14/2014, España, (Segunda Época)

ANSUÁTEGUI ROIG, Francisco, .J., "Las definiciones del Estado de derecho y los derechos fundamentales”, Sistema. Revista de Ciencias Sociales, No 158, 2000.

ARNAUD, André-Jean, “Los juristas frente a la sociedad (1975-1993)”, (trad. I. Lifante y V. Roca), Doxa, n 15-16, 1994.

ATIENZA, Manuel, Curso de argumentación jurídica, $1^{\mathrm{a}}$ edición, Madrid, Trotta, 2016, p. 29. (El ejemplar citado corresponde a la $4^{\mathrm{a}}$ reimpresión de la $1^{\mathrm{a}}$ edición de 2013.

El sentido del derecho, Barcelona, ed. Ariel, 2013.

Las razones del derecho. Teoría de la argumentación jurídica, México, IIJUNAM, 2007.

${ }^{121}$ BERMAN, H., íd., p. 21. 
“Sobre la única respuesta correcta,” Revista Jurídicas, Vol. 6, n² 2, Colombia, Julio-Diciembre, 2009.

ATIENZA Manuel, /RUIZ MANERO, Juan, Las piezas del derecho, Barcelona, Ariel, 1996.

ARIAS EIBE, Manuel, José., "Funcionalismo penal moderado o teleológico-valorativo versus funcionalismo normativo o radical”, Doxa, Cuadernos de Filosofía del Derecho, $\mathrm{n}^{\circ}$ 29, 2006.

BARROSO, Luis Roberto, El neoconstitucionalismo y la constitucionalización del derecho, México, D.F., IIJ-UNAM, 2008.

BAUMAN, Zygmunt, / DONSKIS, Leónidas, Ceguera moral. La pérdida de sensibilidad en la modernidad líquida, Barcelona, Paidós, 2015.

BERMAN, Harold, Law and Revolution, The Harvard University Press, 1983.

BIDART CAMPOS, Germán, Teoría general de los derechos humanos, Buenos Aires, ed. Astrea, 1991.

BOURCIER Daniéle, Inteligencia artificial y derecho, Barcelona, Universitat Oberta de Catalunya, 2003.

CARBONELL Miguel, /SALAZAR, P., La reforma constitucional de derechos humanos: un nuevo paradigma, México, D.F., ed. Porrúa, IIJ-UNAM, 2011

CÁCERES NIETO, Enrique, "Las teorías jurídicas como realidades hermenéuticas”, Boletín Mexicano de Derecho Comparado, nueva serie, año XXXV, núm. 103, enero-abril de 2002.

Institucionalismo jurídico y constructivismo social, Boletín Mexicano de Derecho Comparado, nueva serie, año XXXIV, núm. 100, enero-abril de 2001.

CARBONNIER, Jean, Derecho flexible. Para una sociología no rigurosa del derecho, Madrid, Tecnos, 1974. (Traducción y prólogo de L. Díez-Picazo).

CARLOS ESPINOSA, Alejandro, "Criminología de la posmodernidad. Una lectura de derecho penal regional”, en, AA.VV. Entre libertad y castigo: dilemas del estado contemporáneo, México, IIJ-UNAM, Facultad de Derecho, $1^{\text {a }}$ ed., 2011.

CARRIÓ, Genaro. R., Notas sobre derecho y lenguaje, Buenos Aires, Ed. Lexis-Nexis, $5^{\mathrm{a}}$ Edición, 2006.

CARPIO MARCOS, Edgar, "Bloque de constitucionalidad y proceso de inconstitucionalidad de las leyes”, Revista Iberoamericana de Derecho Procesal Constitucional, Vol. 4, ed. Porrúa, 2005.

COSSÍO DÍAZ, José, Ramón, “Las trampas del consenso”, Revista Nexos, octubre 2013.

CORZO SOSA, Edgar, "Control constitucional, instrumentos internacionales y bloque de constitucionalidad”, en FERRER MAC-GREGOR, Eduardo y ZALDÍVAR LELO DE LARREA, Arturo, La ciencia del derecho procesal constitucional. Estudios en homenaje a Héctor Fix-Zamudio en sus cincuenta años como investigador del derecho, Tomo IV. Derechos fundamentales y tutela constitucional, México, D.F., IIJ-UNAM, 2008.

CRUZ, Luis. M., La Constitución como orden de valores. Problemas jurídicos y políticos, Granada, España, Editorial Comares, 2005. 
DE ASÍS ROIG, Rafael, Una mirada a la robótica desde los derechos humanos, Madrid, UC3-Dykinson, 2015.

DELOS REYES ARAGÓN, Wilson, “Algunos elementos para construir una definición de derechos humanos”, Revista Estudios Socio-Jurídicos, Vol. 10, No 2, JulioDiciembre, 2008.

DAMASIO, R. A., El error de Descartes, Barcelona, ed. Andrés Bello, 1996.

DE TRAZEGNIES GRANDA, Fernando, Postmodernidad y Derecho, Bogotá, Colombia, ed. Temis, 1993.

DEL REAL ALCALÁ, Alberto, “Cuestionamiento del ideal de certeza en el Derecho: HartZagrebelsky-Endicott”, México D.F., IIJ-UNAM, Boletín Mexicano de Derecho Comparado, núm. 131, 2011.

DWORKIN, Ronald, El dominio de la vida, Barcelona, Ariel, 1996. (Trad. Ricardo Caracciolo y Víctor Ferreres).

El Imperio de la justicia, Barcelona, Gedisa, 2a Edición 1992. (Traducción Claudia Ferrari).

Los derechos en serio, Barcelona, Ariel derecho, $1^{\circ}$ Edición 1984. (Traducción Marta Guastavino)

DZIB AGUILAR, J. Paulino, Manual Práctico de Psicología Forense, Mérida, Yuc., México, Universidad Autónoma de Yucatán, 2013.

ENDICOTT, Timothy, La vaguedad en el derecho, Madrid, Ed. Dykinson, 2007. (Trad. J. Alberto del Real y Juan Vega).

“El derecho es necesariamente vago”, Derechos y Libertades, No 12, 2003.

ESTRADA VÉLEZ, Sergio Iván, Los principios jurídicos y el bloque de constitucionalidad, Colombia, Universidad de Medellín, 2005.

FARIÑAS, María José, Los derechos humanos: Desde la perspectiva socio-jurídica a la actitud postmoderna, Madrid, Ed. Dykinson, 1997.

FASSÓ, Guido, Historia de la Filosofía del Derecho 3. Siglos XIX y XX, Madrid, Ediciones Pirámide, 1996.

FAVOREU, Louis "El Bloque de Constitucionalidad”, Revista del Centro de Estudios Constitucionales, Madrid, № 5. Enero-marzo 1990.

FERRARI, Vincenzo, Giustizia e diritti umani. Osservazioni sociologico-giuridiche, Milano, Ed. Franco Agneli, 2007.

A sociological theory of law, Milano, Giuffré Editore, 1991.

FLORES SALDAÑA, Antonio, El control de convencionalidad y la hermenéutica constitucional de los derechos humanos, México, D.F., ed. Porrúa, 2014.

GADAMER, Hans-Georg. Verdad y método, fundamentos de una hermenéutica filosófica, II, $2^{a}$ ed., ediciones Sígueme, Salamanca, 1994.

GARCÍA FIGUEROA, Alfonso, Criaturas de la moralidad, una aproximación neoconstitucionalista al derecho a través de los derechos, Madrid, Trotta, 2009.

"El no positivismo principialista en Il diritto mite de Gustavo Zagrebelsky", Anuario de Filosofía del Derecho XIII, (1996).

GARCÍA INDA, Andrés, "Cinco apuntes sobre Derecho y postmodernidad”, Doxa, Cuadernos de Filosofía el Derecho, n² 24, 1989. 
GEIGER, Theodor, Estudios de sociología del derecho, México D.F., Ed. Fondo de Cultura Económica, 1983.

GÓMEZ GONZÁLEZ, Arely, Reforma penal 2008-2016. El Sistema Penal Acusatorio en México, Ciudad de México, INACIPE, $1^{\text {a }}$ ed. 2016.

GONZÁLEZ ORDOVÁS, María José, Ineficacia, Anomía y Fuentes del Derecho, Madrid, Ed. Dykinson-Universidad Carlos III, 2003.

GRAU, Eros, Interpretación y aplicación del derecho, Madrid, ed. Dykinson, 2007.

GRÜN, Ernesto, "El derecho posmoderno: un sistema lejos del equilibrio”, Revista Telemática de Filosofía del Derecho, n¹, 1997.

GUASTINI, Riccardo, Nuevos estudios sobre la interpretación, Colombia, Universidad de Externado de Colombia, 2010, (Traducción de Diego Moreno Cruz).

GUTIÉRREZ GUTIÉRREZ, Ignacio, “Criterios de eficacia de los derechos fundamentales en las relaciones entre particulares”, Teoría y Realidad Constitucional, № 3, 1999.

HÄBERLE, Peter, La libertad fundamental en el Estado Constitucional, Lima, Fondo Editorial de la PUCP, 1997.

HALliVIS PELAYO, Manuel, Teoría general de la interpretación, México, D.F., ed. Porrúa, 2012.

HART, Herbert, L.A., El concepto de derecho, Buenos Aires, Ed. Abeledo-Perrot, 1995. (Trad. Genaro R. Carrió).

HESSE Konrad, Escritos de derecho constitucional, Madrid, 2da. Ed. Centro de Estudios Constitucionales, 1992. (Traducción de Pedro Cruz Villalón).

HESSEL, Stéphane, ¡Indignaos!, Barcelona, ed. Destino, 2011, p. 4. (Trad. Telmo Moreno Lanaspa).

ITURRALDE SESMA, Victoria, Lenguaje legal y sistema jurídico. Cuestiones relativas a la aplicación de la ley, Madrid, Ed. Tecnos, 1989.

JAKOBS, Günther, "Derecho penal del ciudadano y Derecho penal del enemigo", en, Derecho penal del enemigo, Madrid, Cuadernos Civitas, 2003. (Trad., de M. Cancio Meliá).

“Sobre la génesis de la obligación jurídica”, Doxa, n² 23, 2000. (Trad., de M. Cancio Meliá)

Derecho Penal. Parte General. Fundamentos y teoría de la imputación, Madrid, Civitas, $2^{\mathrm{a}}$ ed., 1997.

Sociedad, norma y persona en una teoría de un derecho penal funcional, Madrid, Civitas, 1996. (Trad., de M. Cancio Meliá y B. Feijóo Sánchez).

JULIO ESTRADA, Alexei., La eficacia de los derechos fundamentales entre particulares, Bogotá, Universidad Externado de Colombia, 2001.

KELSEN, Hans, ¿Qué es la justicia?, México, Fontamara, trigésima edición, 2016.

LAPORTA Francisco, J., "Principio de igualdad: introducción a su análisis”, Sistema. Revista de Ciencias Sociales, Nº 67, 1985.

LARA RIVERA, Jorge. Alberto, "La figura del arraigo es pertinente y cumple cabalmente criterios de derechos humanos”, Defensor, Revista de Derechos Humanos, CDHDF, Nº2, año X, febrero 2012. 
LASZLO Erwin, La gran bifurcación. Crisis y oportunidad: anticipación del nuevo paradigma que está tomando forma, Barcelona, ed. Gedisa 1990.

LÓPEZ CALERA, Nicolás, M., "Naturaleza dialéctica de los derechos humanos”, Anuario de Derechos Humanos, ${ }^{\circ}$ 6, 1990.

LUHMANN, Niklas, El derecho de la sociedad, México D.F., Ed. Universidad Iberoamericana, 2002. (Trad. Javier Torres Navarrete).

LUNA CASTRO, José Nieves, "Introducción y características generales del nuevo Sistema de Justicia Penal”, en, AA.VV. El nuevo Sistema de Justicia Penal Acusatorio, dese la perspectiva constitucional, México, Consejo de la Judicatura Federal, $1^{\mathrm{a}}$ ed. 2011.

MACEDONIO, HERNÁNDEZ, Carlos, A., “La acción privada de la víctima en el proceso penal acusatorio del Estado de Yucatán ¿el retorno a una acción procesal ineficaz o verdadero beneficio para la víctima?”, en, GORJÓN GÓMEZ, Francisco. J., (Coord.) Mediación Penal y Justicia Restaurativa, México, Tirant lo Blanch, $1^{\mathrm{a}}$ ed. 2014.

MANNHEIM, Karl, Ideología y utopía, México D.F., Ed. Fondo de Cultura Económica, 1987. (Trad. Salvador Echavarría).

MARSHALL MCLUHAN, Herbert, Comprender los medios de comunicación. Las extensiones del ser humano, Barcelona, Paidós, 1996.

MARTÍNEZ BAHENA Goretty, C., "La inteligencia artificial y su aplicación al campo del derecho", Alegatos, n 82, 2012.

MEDINA MORA, Alejandra, F., SALAZAR UGARTE, Pablo, VÁZQUEZ Daniel, Derechos humanos y restricciones. Los dilemas de la justicia, México, ed. Porrúa, UNAM, 2015.

MOFFITT'S, Terrie, E., “The neuropsychology of conduct disorder”, Development and Psychopathology, $\mathrm{n}^{\circ}$ 5, 1993.

MONTORO BALLESTEROS, Alberto, "El funcionalismo en el Derecho: notas sobre N. Luhmann y G. Jakobs”, Anuario de Derechos Humanos. Nueva Época. Vol. 8, 2007.

MORALES MORALES, A. V., ODIMBA ON'ETAMBALAKO WETSHOKONDA, J. C. "La incorporación del concepto de bloque de constitucionalidad en materia de derechos humanos en México”, Prolegómenos. Derechos y Valores, 2011.

MORGAN, A.B., \& LILIENFELD, S.O. "A meta-analytic review of the relation between antisocial behavior and neuropsychological measures of executive function", Clinical Psychology Review, n² 20, 2000.

NASH ROJAS, Claudio, La concepción de los derechos fundamentales en Latinoamérica, México D.F., Ed. Fontamara, 2010.

OST, François, “Júpiter, Hércules, Hermes: tres modelos de juez”, Academia, Revista sobre la Enseñanza del Derecho, Universidad de Buenos Aires, año 4, n 8, 2007. Publicado originalmente en Doxa, $\mathrm{n}^{\circ} 14,1993$.

PARMA Carlos, Derecho penal posmoderno, Perú, Ara editores, 2005.

PECES-BARBA MARTÍNEZ, Gregorio, Curso de derechos fundamentales. Teoría general. Madrid, Universidad Carlos III de Madrid, 1999. 
PÉREZ HUALDE, Alejandro, "Reflexiones sobre el neoconstitucionalismo y derecho administrativo”, en, BÉJAR RIVERA, Luis José (Coord.), Derecho Administrativo. Perspectivas Contemporáneas, México, D.F., ed. Porrúa, México, 2010.

PÉREZ TREMPS, Pablo., Escritos sobre justicia constitucional, México D.F., Ed. Porrúa

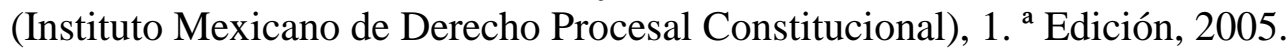

PÉREZ TRIVIÑO, José L., De la dignidad humana y otras cuestiones jurídico-morales, México, D.F., Fontamara, $1^{\mathrm{a}}$ ed. 2007.

PISCITELLI, Alejandro, Ciberculturas en la era de las máquinas inteligentes, Buenos Aires, Paidós, 1995.

PORTILLA CONTRERAS, Guillermo, (Coord.) Mutaciones de Leviatán. Legitimación de los nuevos modelos penales, Andalucía, España, ed. AKAL, 2005.

PRIETO SANCHÍS, Luis, Justicia constitucional y derechos fundamentales, Madrid, Trotta, 2003.

"El Constitucionalismo de los derechos", en, CARBONELL, M., (Editor), Teoría del Neoconstitucionalismo, México. Trotta-UNAM, 2007.

RAMELLI ARTEAGA, Alejandro, "Sistema de Fuentes del Derecho Internacional Público Bloque de Constitucionalidad”, en, Eduardo MONTEALEGRE LYNETT, Eduardo, (Coord.), Anuario de Derecho Constitucional, Análisis de la Jurisprudencia de la Corte Constitucional de Colombia, Bogotá, Universidad Externado de Colombia, $1^{\mathrm{a}}$ ed. 2003.

RICOEUR, Paul, Sí mismo como otro, Madrid, Siglo XXI, 1998.

RODRÍGUEZ ZURITA, Fabiola, El grado de culpabilidad: directrices para lograr la eficacia en el nuevo Sistema Penal Acusatorio en México, Ponencia inédita, México, 2017.

PRIETO NAVARRO, Evaristo, "La teoría de sistemas de Luhmann y el derecho", en, GARCÍA AMADO, Juan, (Coord.), El derecho en la teoría social. Diálogo con catorce propuestas actuales, Madrid, Ed. Dykinson, 2001.

ROSZAK, Theodore, El culto a la información. Un tratado sobre, alta tecnología, inteligencia artificial y al verdadero arte de pensar, Barcelona, Gedisa, 2005.

ROXIN, Claus, "Zur Kriminalpolitischen Fundierung des Strafrechtssystems", em Festschrift für Günther Kaiser, Berlin, Duncker \& Humblot, 1998.

RUBIO LLORENTE, Francisco, "Bloque de constitucionalidad" Revista Española de Derecho Constitucional, año 9, número 27, septiembre-diciembre 1989,

RUZ SALDÍVAR, Carlos, / MALDONADO MÉNDEZ, Erika, Reflexiones sobre la constitución como la norma fundamental a la luz del nuevo orden jurídico internacional, ponencia inédita presentada en el XIII Congreso Iberoamericano de Derecho Constitucional, Ciudad de México, 2017.

SALAZAR UGARTE, Pedro, "Garantismo y neoconstitucionalismo frente a frente: algunas claves para su distinción”, Doxa, Cuadernos de Filosofía del Derecho, n 34, 2011.

SÁNCHEZ GIL, Rubén, "Hacia un nuevo modelo de interpretación constitucional", Revista de la Facultad de Derecho de México, México, UNAM, Facultad de Derecho, t. LVIII, núm. 249, enero-junio de 2008. 
SARTORI, Giovanni, Homo videns. La sociedad teledirigida, Argentina, Taurus, 1998.

SANTOS, Boaventura de Sousa, De la mano de Alicia y lo político en la postmodernidad, Santafé de Bogotá, Siglo de Hombre Editores, 1998. (Trad. De C. Bernal y M. García Villegas).

SCHMITT, Carl, El concepto de lo político, Madrid, ed. Alianza, Ciencias Sociales, 2002.

SCHWABE, Jürgen. (Coomp.), Jurisprudencia del Tribunal Constitucional Federal Alemán. Extractos de las sentencias más relevantes, México, D.F., KonradAdenauer-Stiftung, 2009.

UROSA RAMÍREZ, Gerardo. A. "Algunas reflexiones en relación con el "derecho penal del enemigo" dentro del contexto nacional”, Revista de la Facultad de Derecho de México, vol. 61, n 255, UNAM, 2011

VENEGAS GRAU, María, Derechos fundamentales y derecho privado. Los derechos fundamentales en las relaciones entre particulares y el principio de autonomía privada, Madrid-Barcelona, Ed. Marcial Pons, 2004, (prólogo de Rafael de Asís Roig

ZAGREBELSKY, Gustavo, El derecho dúctil, Madrid, ed. Trotta, 4ª Edición, 2002. (Traducción de Marina Gascón).

ZAGREBELSKY, Gustavo, MARTINI, Carlo María, La exigencia de justicia, Madrid, Minima Trotta, 2006. (Trad. Miguel Carbonell)

ZAMORA FABRA, Jorge Luis, / NÚÑEZ VAQUERO, Álvaro, (Eds.), Enciclopedia de filosofía y teoría del derecho, Vol. I, México, IIJ-UNAM, 2015.

ZULETA PUCEIRO, Enrique, Teoría del Derecho. Enfoques y aproximaciones, Buenos Aires, Lexis Nexis, 2005. 